Pracilual Applications of a

\title{
Spagestation
}

$y^{2}+2$

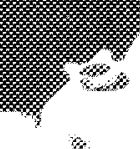

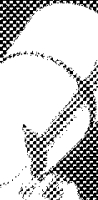

. $1 \%$

\%)

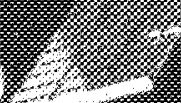
(1)

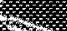

.
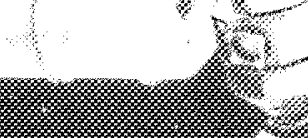

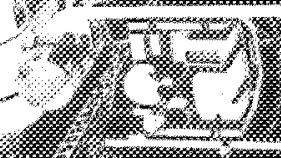
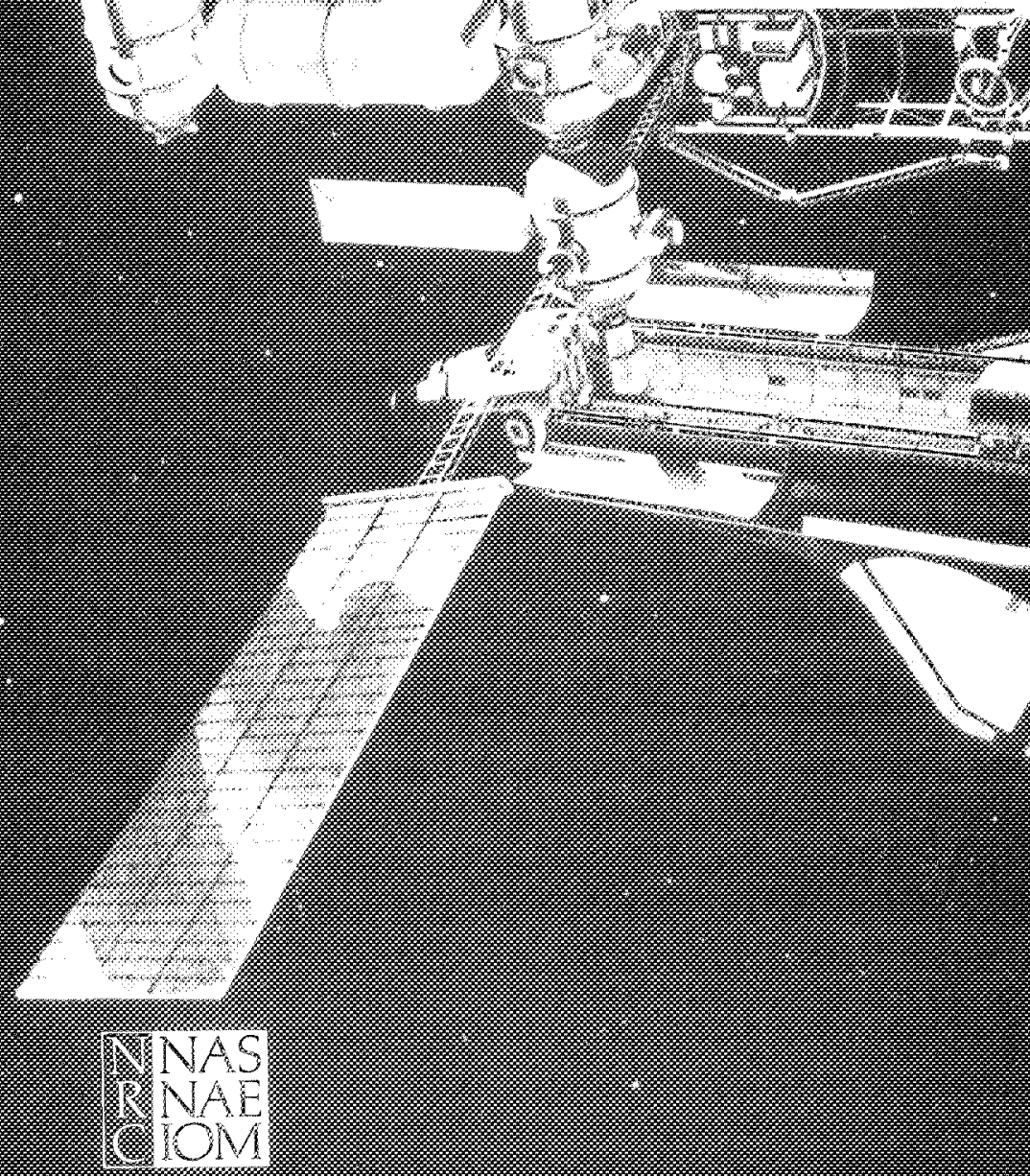


\section{Practical Applications of a Space Station}

Space Applications Board

Commission on Engineering and Technical Systems

National Research Council

NATIONAL ACADEMY PRESS

Washington

1984 
NOTICE: The project that is the subject of this report was approved by the Governing Board of the National Research Council, whose members are drawn from the councils of the National Academy of Sciences, the National Academy of Engineering, and the Institute of Medicine. The members of the panel responsible for the report were chosen for their special competences and with regard for appropriate balance.

This report has been reviewed by a group other than the authors according to procedures approved by a Report Review Committee consisting of members of the National Academy of Sciences, the National Academy of Engineering, and the Institute of Medicine.

The National Research Council was established by the National Academy of Sciences in 1916 to associate the broad community of science and technology with the Academy's purposes of furthering knowledge and of advising the federal government. The Council operates in accordance with general policies determined by the Academy under the authority of its congressional charter of 1863 , which establishes the Academy as a private, nonprofit, self-governing membership corporation. The Council has become the principal operating agency of both the National Academy of Sciences and the National Academy of Engineering in the conduct of their services to the government, the public, and the scientific and engineering communities. It is administered jointly by both Academies and the Institute of Medicine. The National Academy of Engineering and the Institute of Medicine were established in 1964 and 1970, respectively, under the charter of the National Academy of Sciences.

This study by the Space Applications Board was conducted under Contract No. NSR 09-012-106 with the National Aeronautics and Space Administration.

This report is available from the Space Applications Board, National Research Council, 2101 Constitution Avenue, N.W., Washington DC 20418.

Printed in the United States of America. 


\section{SPACE APPLICATIONS BOARD}

George A. Harter, Chairman, TRW Incorporated

James W. Plummer (Chairman until January 26, 1983), Lockheed Missiles and Space Company

George S. Benton, Johns Hopkins University

Ralph Bernstein, IBM Corporation

Donald N. Brown, Ocean Data Systems, Inc.

Jon Davidson, Superior Oil Company

Joseph J. DiNunno, Consultant

Robert T. Filep, Communications 21 Corporation

Robert F. Mills, Decision Images

Hugh Nichols, Howard County, Maryland

J. Robert Porter, Earth Satellite Corporation

John G. Puente, Macom Incorporated

Thomas F. Rogers, Consultant 
Willis H. Shapley, Consultant

John W. Townsend, Jr., Fairchild Space \& Electronics Company

Victoria J. Tschinke1, Florida Department of Environmental Regulation

Elizabeth L Young, Public Service Satellite Consortium

Milton W. Rosen, Executive Director 
STUDY PANELS, OBSERVERS, AND STAFF

Joseph J. DiNunno, Director

PANEL ON EARTH'S RESOURCES

A. Richard Baldwin, Chairman, Cargill Incorporated

G. Robinson Barker, St. Regis Paper Company

John E. Estes, University of California

Sheldon Haas, General Electric Company

Christian J. Johannsen, University of Missouri

Robert F. Mills, New Jersey Department of

Environmental Protection

\section{PANEL ON EARTH'S ENVIRONMENT}

Lawrence R. Greenwood, Chairman, Ball Aerospace Corporation William L. Chameides, Georgia Institute of Technology John W. Firor, National Center for Atmospheric Research

C. Gordon Little, National Oceanic and Atmospheric Administration

Frank R. Malinowski, Santa Barbara Research Center Abraham Schnapf, formerly RCA Astro-Electronics Thomas H. Vonderhaar, Colorado State University

\section{PANEL ON OCEAN OPERATIONS}

James H. Guil1, Chairman, Lockheed Missiles and Space Company

Michael P. Guberek, Scripps Institution of Oceanography Arnold M. Hanson, University of Washington

T. K. Treadwe11, Texas A\&M University 
Donald B. Nowakoski, Chairman, Western Union Gino J. Covie11o, American Satellite Company

Donald K. Dement, Novacom Incorporated

Donald C. MacLellan, Massachusetts Institute of Technology Douglas 0. Reudink, Be11 Telephone Laboratories Thomas F. Rogers, Consultant

Elizabeth L. Young, Public Service Satellite Consortium

PANEL ON MATERIALS SCIENCE AND ENGINEERING

Robert A. Laudise, Chairman, Bell Telephone Laboratories

Norman G. Anderson, Argonne National Laboratory

Martin E. Glicksman, Rensselaer Polytechnic Institute

Kenneth A. Jackson, Bell Telephone Laboratories

Morton E. Jones, Texas Instruments, Incorporated

James Lago, Merck, Sharp and Dohme

David J. Larson, Jr., Grumman Aerospace Corporation

Robert F. Sekerka, Carnegie Mellon University

August F. Witt, Massachusetts Institute of Technology

\section{PANEL ON SYSTEM DESIGN}

Albert E. Sabroff, Chairman, TRW Incorporated James H. Cook, IIT Research Institute Barbara C. Corn, BD Systems Incorporated

J. Allen Cox, Honeywell Systems and Research Center

Robert Morra, Martin-Marietta Aerospace

Robert F. Pelzmann, Jr., Lockheed Missiles and

Space Company

Fritz C. Runge, McDonne11-Douglas Astronautics

David H. Staelin, Massachusetts Institute of Technology 


\section{OBSERVERS}

National Aeronautics and Space Administration

Ivan Bekey

Dixon Butler

William T. Carey

Philip E. Culbertson

James A. Dunn

Burton I. Edelson

Frank Garcia

Don Gerke

Daniel H. Herman

Stephen S. Holt

Ray Hook

Robert R. Love 11
Dudley G. Mcconne11

Robert Naumann

Mark B. Nolan

William A. Oran

William L. Piotrowski

William P. Raney

Jack Salzman

William C. Snoody

Lou is R. Testardi

Shelby Tilford

James C. Welch

De11 P. Williams III

National Oceanic and Atmospheric Administration

James Purdom

John Sherman

Harold Yates

U.S. Department of Agriculture

Richard A. McArdle

Bureau of Land Management

David W. Allen

Office of Technology Assessment

Philip P. Chandler

European Space Agency

Ian W. Pryke

vii 
SPACE APPLICATIONS BOARD STAFF

Milton W. Rosen, Executive Director (after July 23, 1983) Clotaire Wood, Executive Director (until July 8, 1983) Laurence F. Gilchrist, Deputy Director Victoria M. Benjamin, Administrative Assistant Barbara A. Candland, Administrative Assistant (until October 7, 1983)

Betty S. Brown, Administrative Secretary 


\section{PREFACE}

In the spring of 1982, the Space Applications Board was asked to conduct a study about the potential uses of a space station for civil and commercial applications. The request came from NASA's Office of Space Science and Applications. The study was to be only one of several agency and contractor studies aimed at developing and evaluating requirements for a manned space station program. In requesting the study, NASA made it clear that the justification for development of a space station must be based on many considerations, of which space applications would be only a part. The Space Applications Board accepted the assignment, with a goal of providing an objective assessment of a manned space station, or, alternately, a large unmanned space platform, for use in satisfying future application program requirements.

To conduct the study, the Board brought together about 30 recognized experts from the various user communities. The group spent a week at Snowmass, Colorado, engaged in an intensive effort to address the following study tasks:

Review space applications requirements for the $1990 \mathrm{~s}$ Identify desired technological advances Identify requirements for a space station to facilitate applications programs Assess the utility of a human presence to space applications

The group was not asked to evaluate the cost effectiveness of a space station relative to other possible alternatives. The assignment was to determine possible future application program needs, and then to assess how well a space station might satisfy those needs. 
The summer study participants were divided into panels representing five user-oriented communities, and a sixth panel dealing with system design considerations. The system design panel examined requirements of the various applications missions from the standpoint of commonality, and with an objective of defining technical requirements that could be used for the conceptual design of a space station.

Each of the five user panels was structured to represent applications programs with similar characteristics. The Earth's Resources Panel dealt with applications of remote sensing for resource assessment in such user areas as agriculture, hydrology, and mineral exploration. The Earth's Environment Panel dealt with the earth's atmosphere and its impact on society, and gave consideration to upper atmosphere research, global chemical cycles, weather, and climate. The Ocean Operations Panel looked at both science and applications and considered subjects such as coastal preservation, fisheries development, mineral extraction, ocean pollution, sea ice monitoring, oil and gas exploration, and commercial shipping. The Satellite Communications Panel assessed the potential role of a space station in the evolution of commercial telecommunication services up to the year 2000. The Materials Science and Engineering Panel focused on the utility of a space station environment for materials processing. One early problem for the panels was lack of a clear definition of space station capability or constraints. For purposes of the study, it was assumed that the station would be a large platform, capable of housing a wide array of diverse instruments, and could be either manned or unmanned.

I take this opportunity to express my deep appreciation to the panel chairmen and the panel members for the concentrated effort that was required to produce the chapters of this report. Observers and resource persons from NASA, NOAA, and other agencies of government and industry were helpful in providing information and comment. Finally, I wish to thank the Space Applications Board staff for their work in preparing this report for publication.

George A. Harter Chairman

Space Applications Board 


\section{CONTENTS}

\section{EARTH'S RESOURCES}

Introduction $\ldots \ldots \ldots \ldots \ldots \ldots \ldots \ldots \ldots \ldots \ldots \ldots \ldots \ldots \ldots$

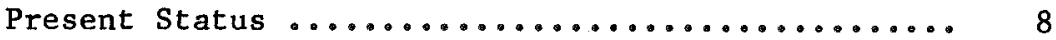

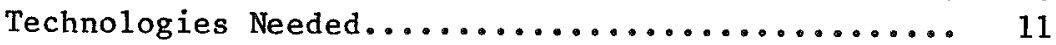

Possible Uses of a Space Station to Support

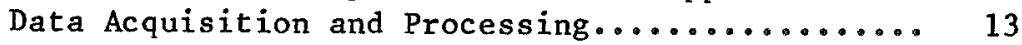

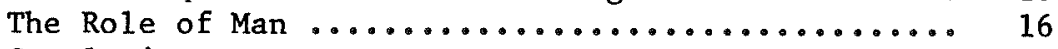

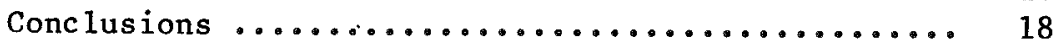

\section{EARTH'S ENVIRONMENT}

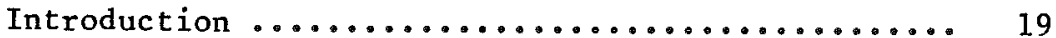

Upper-Atmospheric Research ..................... 20

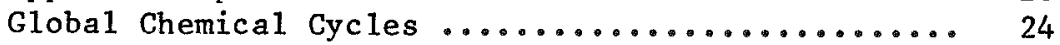

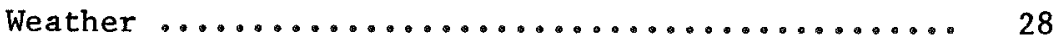

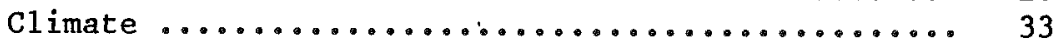

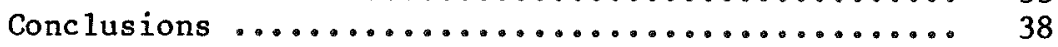

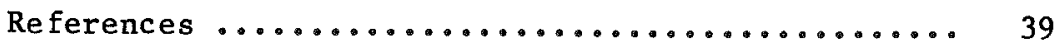

\section{OCEAN OPERATIONS}

Introduction ................................... 41

Current Status of Remote Sensing of the Oceans .... 43

The Need for Ocean Data--Major Uses ............. 46

Requirements for Spacecraft for Oceanic

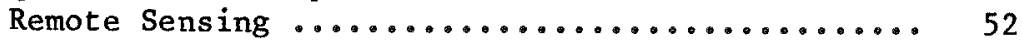

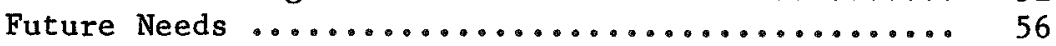

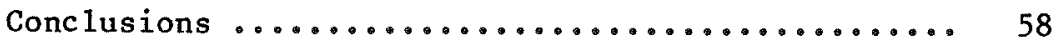

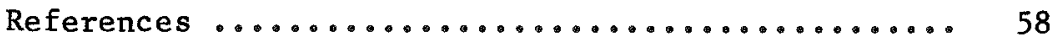




\section{SATELLITE COMMUNICATIONS}

Major Domestic Satellite Communications Services .. 60

Developments Expected Through the 1980s ......... 66

Potential New Services, 1990-2000 .............. 67

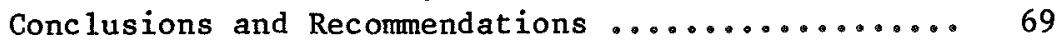

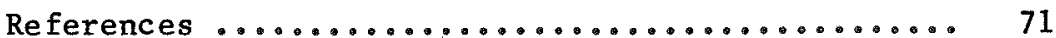

MATERIALS SCIENCE AND ENGINEERING

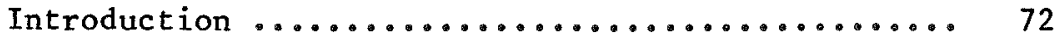

Brief History of NASA's Materials Processing

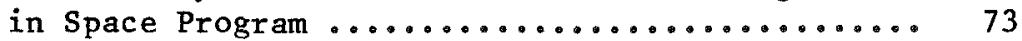

Present Status of NASA's Materials Processing

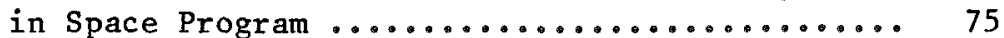

The Role of Man in Space ................... 79

Materials Science and Engineering Requirements

for a Space station ..................... 81

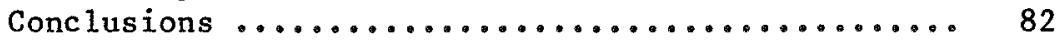

\section{SYSTEM DESIGN}

User Design Requirements ........................ 84

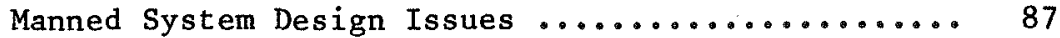

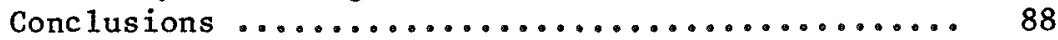




\section{OVERVIEW}

The demonstrated capabilities of the Space Shuttle and rapid advancements in both ground- and space-based technology offer new opportunities for developing space systems for practical use. It soon may be possible, for example, to assemble large structures in space, to revisit and refurbish spacecraft, and to provide the large amounts of electric power in space that some uses would require. Large-scale integrated circuits offer new possibilities for control of spacecraft functions and for data handling that would be of great importance in certain applications. These and other capabilities may make it possible to carry out some activities in space at lower cost than before, and also to achieve objectives not previously considered realistic.

In view of these capabilities and the anticipated national requirement for human presence in space on a long-term basis, the National Aeronautics and Space Administration (NASA) is studying the possibility of developing a manned space station and, in conjunction with the station, one or more unmanned space platforms. At NASA's request, the Space Applications Board (SAB) of the National Research Council conducted a study to determine the technical requirements that should be considered in the conceptual design of a space station and/or space platform so that, if developed, these spacecraft would have utility for practical applications.

The SAB study, conducted in August 1982, consisted of the deliberations of five user-oriented panels, one in each of the following areas: (1) earth's resources, (2) earth's environment, (3) ocean operations, (4) satellite communications, and (5) materials science and engineering. A sixth panel, which dealt with system 
design factors, helped examine areas of commonality among the requirements of the various applications.

Each user-oriented panel was asked to consider what practical applications of space systems may be expected in their particular areas beginning about the year 1990. The panels were asked also to identify technological progress that would need to be made and that should be emphasized in order for space systems with practical uses to have greater utility by the time a space station or space platform might be available. In addition, other issues of major importance--e.g., the need for human presence in space, desired orbits of spacecraft, and major new devices that the various applications would require--were to be addressed.

On 15 October 1982, the Space Applications Board sent NASA an interim response based on the study. This formal report of the study consists of six chapters, one for each use area and one on system design. The following overview is a summary of the findings and recommendations of the six panels and some overall conclusions.

The Earth's Resources Panel considered the application of remote sensing for assessing such resources as crops, forests and rangelands, minerals and petroleum, water, and land. Satellite remote sensing is a relatively new information source, providing a means to survey and inventory a wide array of earth resources. It provides a capability to monitor changes and, by predictive modeling, to provide a forecast for the future. Use of this new capability is still in its infancy, and much further study and development will be required for its full exploitation.

A diversity of requirements for the several application areas were uncovered. However, some basic mission requirements seem to be common for virtually all applications. The most important of these are a space station, or an unmanned platform, in a low, near-polar, sun-synchronous orbit; a variety of sensors that can operate continuously and interactively; a data format that merges the outputs from a disparate set of sensors; timely delivery and archiving of data for the user communities; and a commitment to long-term continuity of data acquisition and distribution.

Onboard data processing is important for almost all remotely sensed data streams, and a highly trained individual might be useful in the operation of the onboard processing system, although this might be accomplished by 
ground control. A human presence would be most important during the research or exploratory phase of a new remote sensing program. Even in an operational phase, man's ability to identify transient phenomena, to monitor data quality, to adjust instruments rapidly, and to make in-situ decisions on data handling could prove useful.

The Earth's Environment Panel addressed four broad applications of remote sensing: upper atmosphere research, global chemical cycles, weather, and climate.

Several important roles for a space station were foreseen. First, it could permit use of many different sensors to make simultaneous observations of chemical species, with onboard processing and merging of the data. Second, a human presence could enable a frequent recalibration of instrumentation. In this respect, the station could play a valuable role in comparing data from onboard sensors with that obtained by other free-flying satellites. Other possibilities are the servicing of instruments, including the replenishment of cryogenic coolant and the periodic maintenance, repair, and replacement of sensor packages. Finally, a space station could facilitate the use of active sensor payloads, such as lidar or microwave sounders, which because of their large size and power requirements have been regarded as beyond the near-term capabilities of free-flying satellites. Most environmental observations would prefer a low, near-polar, sun-synchronous orbit.

There are benefits and disadvantages associated with a human presence. On one hand, humans can contribute to the calibration and servicing of instruments. On the other hand, a number of potentially serious problems could develop, such as the impact of human presence on sensor pointing accuracy and stability, or the possibility of contamination in and around the vehicle. More study of the human role is required before a determination can be made.

The Ocean Operations Pane1 looked at a wide variety of space applications, including coastal preservation, fisheries, oil and gas exploration, ocean pollution, sea ice monitoring, mineral extraction, and commercial shipping. There is a growing need for more and better data about the oceans. The needs are diverse, and are currently dispersed among many agencies, organizations, and individuals. 
Only satellite-borne sensors can provide broad area data coverage of the world's oceans. Hence, more emphasis should be placed on collecting data and making it available to ocean users in a timely manner, on a daily basis for some users. Since data is required for regions that extend to the earth's poles, high-inclination orbits are desired for most applications. A low, near-polar, sun-synchronous orbit would fill most requirements.

With regard to the benefits of a human presence, the Ocean Operations and the Earth's Environment panels came to the same general conclusion: there is no meaningful role for man in the acquisition of data. However, a manned space station could provide the capability for modification and repair of sensors and spacecraft in orbit. For example, the $\$ 125 \mathrm{million}$ Seasat oceanographic satellite probably could have been restored to operation if a means had been provided for its retrieval and repair.

The Satellite Communications Panel surveyed projected communications services for the period from 1990 to 2000 and concluded that a manned space station would offer little benefit during this period. In addition, communication satellites need to be located in synchronous, geostationary orbits. The launch capability provided by the Shuttle-Centaur combination is adequate for all requirements envisioned prior to the year 2000 .

However, some ancillary uses of a space station at low earth orbit were envisioned. The station might serve as a fuel depot and base of operations for assembling and launching satellites to synchronous orbit, with the possible benefit of reducing launch costs or allowing launch of heavier payloads. Also, use of a low-orbit station for conducting some communication experiments, such as the deployment and evaluation of very large antennas, is possible.

The Materials Science and Engineering Panel envisioned a space station that would provide a laboratory staffed with technically trained operators. The materials community would make good use of a space station if it were to be developed.

Several key requirements for a space station laboratory were identified. In addition to a low-gravity environment, materials processing requires a relatively large amount of electric power and needs facilities for 
cooling hot materials in a controlled manner. The usefulness of a space station laboratory would depend, in large part, on the qualifications and experience of the technical staff manning the facility. The need for one or more trained scientists to perform the materials experiments is foreseen, with at least one experienced technician to maintain, repair, and modify the processing equipment.

A space station could provide some important advantages over the current shuttle capability. Chief among these would be the much longer flight time and the possibility of less interference from firings of the attitude control thrusters. The ability to carry out weeks, or even months, of interactive materials experimentation in a space station would represent a great improvement over use of the Space Shuttle spacelab.

The System Design Panel did not address a specific applications area; rather it focused on system design and integration issues that apply to the space station concept.

Two novel concepts were identified for further study and analysis. One involves the use of real-time communication coupled with remote control to provide an operator on the earth's surface the capability to carry out complex operations within the space station. This rea1-time, closed-1oop control is called telepresence, and is put forth as a complementary role to human presence for some space station operations. It features two new technologies--wideband, high-data-rate telecommunications and computer-controlled robotics.

Another concept is the development of a space service station, which would tend the in-orbit needs of unmanned satellites and space platforms. Functional capabilities would include repair, servicing, and replacement of expendables for various types of instruments and spacecraft.

The System Design Panel recommended that NASA develop design rules for a number of important space station concepts, including system modularity, subsystem interfaces, and technology upgrading. Early definition of modular system architecture and subsystem interfaces would be very helpful in guiding industry's developmental work on a space station. 
In summary, we find that most remote sensing applications require sensor payloads in a low, near-polar, sun-synchronous orbit. This suggests that the space station program should include a multifunctional sensor platform in a near polar orbit, with propulsion capability to accommodate mission-dependent orbit changes. The platform should include a variety of sensors to serve the many earth resource, meteorological, and ocean operations communities.

We feel that if a space station is developed, its effective utilization will need significant resources beyond those required for the space station alone. There should be as much of a commitment to payload development as there is to the station itself. Therefore, it is essential that NASA consider not only the anticipated costs of developing the station, but also the envelope of total system costs, including payload development.

Finally, we recommend that NASA give serious consideration to a novel system concept that we call telepresence. At a minimum, telepresence would provide an important complementary capability to the functions made possible by a human being in space. Rapid advances in space communications and robotics seems to offer great potential for real-time control of many space station or space platform operations by an operator on the ground. 


\section{EARTH'S RESOURCES}

\section{INTRODUCTION}

The Earth's Resources Panel considered the traditional areas included in the study of the earth's renewable and nonrenewable resources: agriculture, forestry, rangeland, geology, water resources, and land use. Remote sensing involves such functions as locating features on the earth and mapping them, measuring geological phenomena, studying water quality and quantity, and making studies of land use patterns. The primary benefit of satellite data to the earth's resources community is that they provide a current synoptic view from space that makes it possible to detect patterns and to recognize features not readily seen in conventional data. A notable geological example is the detection, in Landsat images, of previously unrecognized extensions of the San Andreas fault in California.

Activities related to research on or management of renewable or nonrenewable resources may be grouped into three phases: inventory/survey, monitoring, and predictive modeling. In the inventory/survey phase, the quantity and quality of the resource of interest within a specific area are determined--for example, forest coverage in a particular geographic area. Monitoring involves detecting changes in the resource of interest, such as determining forest coverage increase or decrease from year-to-year. Predictive modeling yields an analysis of trends within a given area that, when coupled with environmental, socioeconomic, and political information, would facilitate or improve management decisions. For example, data and information from inventory/survey and monitoring activities would be used to drive mathematical models so that a decision to cut a timber stand in order to permit a residential development could be based on a rational analysis. 
The degree to which a space station or space platform contributes to more effective or more efficient production of remotely sensed data will determine its utility for earth resources applications. The Panel reviews each of the earth resources areas, then comments on what is needed to improve the utility of remotely sensed data to the earth resources community and discusses the role of man in space.

\section{PRESENT STATUS}

Since the launch of the first Landsat in July 1972, many investigations have shown the usefulness of remote sensing for earth's resources exploration management. In some cases, operational activities have been established using satellite data. For instance, there have been demonstrated benefits from locating and mapping of vegetative cover (crops and forests), and from observations of geologic phenomena, water quantity and quality, and land use patterns.

Unfortunately, because of problems with data processing, handling, and distribution--and more recently because the continuity of Landsat data is unpredictable--few of these applications can be considered operational in terms of meeting users' needs. Although processing and distribution have improved over the past ten years, at present the elapsed time between data acquisition and receipt of data by the potential user is still too long for many important applications. In some cases, the amount of data correction that must be done by the user before information can be extracted from the data is substantial.

\section{Agricu1ture, Forestry, and Rangeland}

Agriculture, forestry, and rangeland activities cover a variety of renewable resources that are heavily dependent on human activity. In general, these resources are managed on a cyclical basis in which harvest, regeneration, and intermediate cultural activity play dominant roles. Also, the management of agriculture, forest, and rangeland is severely affected by vagaries of weather and by the effects of fire, wind, and water.

Earth observation programs employing remotely sensed data have been used extensively in agricultural 
applications. Landsat data have been used to produce detailed crop information for large areas. The LACIE (Large Area Crop Inventory Experiment) project demonstrated the utility of processed Landsat information combined with other data to develop estimates of worldwide wheat production.

Other common Landsat applications in agriculture include the monitoring of irrigated. lands and assessment of water needs, determination of the location and spread of crop disease and insect infestations, detection of salinity, and mapping of general agricultural land capability. For example, Landsat data were used to update the inventory of four million acres of irrigated lands along the Snake River in Idaho--a task that the time and cost of conventional techniques had ruled out for the past decade.

\section{Minerals and Petroleum Exploration}

Satellite images combined with other forms of data have helped in maintaining inventories and surveys of existing mineral and petroleum resources. Repeat coverage has provided surface change maps that help monitor mining operations and describe progress.

Landsat data have provided a new dimension in the ability to select likely locations for exploration. Geologic applications of remote sensing include geodetic measurements (namely, historical data, patterns of past tectonic activity, and crustal movements), geologic environments (including sedimentary basins, domes, and igneous and metamorphic formations), and episodic events (such as landslides, avalanches, volcanic eruptions, erosion, and coastal change).

\section{Land Water Resources}

Water is an important component of agriculture, forestry, and rangeland use; minerals and petroleum exploration; and land use. Land water resources are different from ocean and estuarine waters; 1 and water resources are those water bodies, surface and subterranean, existing or originating on 1and. These include rivers, streams and creeks, reservoirs, lakes, ponds or other standing water bodies, groundwater and underground water, aquifers, and tables. 
Landsat has been used to conduct watershed inventories that have enabled states to foresee flood problems, drought, and water supply fluctuations. By integrating information on snow depth from ground stations with the snow-covered area estimates obtained from the satellite, accurate predictions can be made of future water runoff and anticipated water supplies within drainage basins.

Landsat can also help states inventory, measure, and monitor surface water levels. As a result of congressional legislation requiring the safety inspection of dams, numerous states have used Landsat computer analysis techniques to identify and map water reservoirs. As an example of the magnitude of this effort, Texas used Landsat data as an aid in the inventory of 4,240 dams, each impounding 50 acre-feet or more of water.

Landsat, with a 16- to 18-day coverage cycle, is an excellent tool for recording fluctuations in water levels caused by drought or flood conditions. The availability of such current information allows states to more quickly and effectively deal with certain types of disasters.

\section{Coastal Zone Management}

The coastal zone programs, resulting from both federal and state legislation, require frequent and current information. This information may vary from delineation of the coastal zone and measurement of the shoreline, to monitoring its erosion and mapping of its vegetative cover and land use changes.

Alabama officials found that conventional methods of shoreline measurement did not meet the needs for repetitive and timely measurement of shoreline erosion. Through Landsat's computerized information, a cost-effective method to more accurately determine shoreline length was developed.

The New Jersey Department of Environmental Protection has used a combination of satellites and aircraft to detect land use changes in the coastal zone. It also has monitored ocean waste disposal and measured shoreline erosion as required for the receipt of federal funds under the Coastal Zone Management Act.

Land Resource Planning and Management

Information on current land development patterns is required for many urban, regional, state, and national 
programs. Landsat can provide information on land use so that changes can be measured quickly and easily.

To date, one of the most successful and beneficial

state applications of Landsat data has been in meeting the requirements for the Enviromental Protection Agency's Section 208 Area-wide Waste-water Treatment Program. A basic objective of the program is to determine the types and distribution of nonpoint sources of water pollution as a basis for developing a plan for their abatement. The states of South Dakota, Ohio, and Illinois, the North Carolina Triangle $\mathrm{J}$, and the Ohio-Kentucky-Indiana Regional Councils of Governments are among numerous state and local governments that use information interpreted from Landsat data to help meet EPA Section 208 requirements.

States often encounter problems when gathering information about the larger geographic areas used for resource development. Land and water inventories necessary for many developmental decisions can be produced quickly and inexpensively using Landsat. In addition, vegetation can be mapped to help determine land capability and wildlife impact. While Landsat can be used effectively for overviews and for selecting areas that require more detailed analysis, more specific information derived through high-altitude photography or ground surveys may be needed for further detailed analysis. However, the general overview from Landsat data is helpful to legislators in determining the location and extent of area in need of policy change.

\section{TECHNOLOGIES NEEDED}

The technologies for earth resources involve sensors, processors, storage, and communications systems. It is felt that these technologies are progressing rapidly, and should be ready for implementation and exploitation in the space station time period.

\section{Sensor Technology}

Space sensor technology has quickly shifted from a photographic silver halide media to multispectral detectors with digital output. Even the multispectral sensors are changing. Complex mirror scan systems are being replaced by linear array "push broom" detectors that 
"sweep" the earth with the satellite motion. These sensors represent the future technologies, but have some deficiencies. The sensors currently used are limited to the visible and near-infrared portion of the electomagnetic spectrum. It is anticipated that a broader spectral range is needed, including the thermal IR. Some advanced push-broom sensors include pointing capability, which is needed in order to be able to acquire images of opportunity that may be off-nadir. This capability will also provide a stereo type of image, useful for geological exploration. Recent experiments have shown that a higher spectral resolution and many spectral bands may be important for improved feature discrimination. Because of the increased data rate that would result, the ability to select the "best bands" will become increasingly important.

\section{Processing Technology}

Digital computers are now used routinely for processing digital images. Both general purpose and special purpose computers are being used. Because of the large amount of data to be processed and handled in future earth observation missions, it is likely that the necessary processor architecture will be one that can support both general and special purpose functions. For example, data management processing can be handled adequately with a general purpose computer, but some complex image processing functions, such as multispectral classification, will require special purpose computers. Some applications, involving many operations on the data, may require parallel processor architecture.

An increasingly important function is to geometrically "merge" diverse data sets into the same geographic coordinates, such that a multitier data base results. This involves geometric manipulation of all sensor data sets for a particular geographic region. This type of data set is particularly useful for analysis and information extraction, but it requires significant processor power.

Once all space station functions have been defined, such as calibration, geometric correction, information extraction, data compression, data presentation, and data handling, an appropriate architecture can be developed. Low power and weight and high performance will be a difficult but important objective. 


\section{Storage}

The space station can serve as an orbiting archive. At the least, it will be necessary to store and assemble data from multiple sensors before distribution to the users. Thus, large memory requirements can result. A current Landsat-4 Thematic Mapper scene consists of about 260 million bytes, which corresponds to about 2 billion bits. If multiple scenes from different sensors are to be combined in the satellite, the onboard requirements could be about 10 billion bits. If the space station serves as an orbiting archive, the storage requirements can be orders of magnitude larger. Low-power storage technologies would be necessary to support these operations.

\section{Communications}

Communications technology has kept up with the demands of space systems. The Tracking and Data Relay Satellite System now supports data rates of 85 million bits per second for Landsat-4, and could provide even greater data rates. However, future operational systems may swamp these capabilities, as there are physical limits to the number of channels and the data rates that they can support. In addition, interference is an increasingly serious problem. When current and future applications are taken into consideration, there will be a deficit of communications channels. It is likely that the space station may decrease the demands upon communications in that the potential exists to convert sensed data into information products that have several orders of magnitude fewer bits than the raw data. If the information products are sent directly to the users, a reduction in the communications and processing requirements may result.

\section{POSSIBLE USES OF A SPACE STATION TO SUPPORT DATA ACQUISITION AND PROCESSING}

Previous unmanned systems for earth observation data acquisition, processing, and distribution have suffered from several problems:

An excess of data

Incomplete calibration of the sensor data A small percentage of the acquired data processed 
Nontimely distribution of the data to the user community

High data costs

The space station may offer an opportunity to improve this situation. At least, it can explore methods, technologies, and procedures to improve and make more efficient the flow of data to the users.

\section{Reducing the Excess of Data}

Past unmanned sensor operation would acquire data during the time the sensor has been programmed to be on. With human control of the operation of space station sensors and systems, there could be a reduction in the amount of data that is acquired. Cloud cover, failed or faulty sensor operation, and other conditions that should inhibit sensor operation could be monitored by a human in the space station and used to control the data acquisition periods. It is likely that images of opportunity could be acquired by an attentive operator, such as fire, storm, and other conditions. In this way, the sensor is focused on the event of interest, improving the information-to-data ratio.

\section{Eliminating or Reducing Defective Sensor Data}

Sensor problems, such as a failed detector, noisy detectors, or incomplete or improper radiometric calibration, are frequently not detected until the data have been received by the ground system. If these problems are not detected on a timely basis, repeat observations need to be scheduled. With an attentive operator in the space station, these kinds of problems could be detected immediately and corrected, reducing the amount of defective data transmitted to the ground.

\section{Improving the Percentage of Processed Data That Is Acquired}

The space station provides the potential for having an intelligently controlled platform and sensor. Thus, nearly all data that are requested are reliable and $c a n$ be used and processed. Further specific data requests could 
be scheduled, acquired, and specially processed for the user. These data could be directly disseminated to the user after acquisition and preprocessing, thus reducing the need for additional backup data. With sufficient processing capability on the space station, information extraction operations, such as multispectral

classification and principal component analysis, could be performed, thus reducing the amount of bits that need to be transmitted and providing information products directly to the user.

\section{Providing Data on a Timely Basis to the User}

Previous systems have provided data to the user late; weeks or even months have elapsed from the time of data acquisition. As some of the data are perishable--that is, they have little value if conditions have changed (this is particularly important in agriculture and hydrology)--this can be a serious problem to the user. It is likely that, if sufficient data processing capability exists on the space station, processed data and even information products could be sent directly to the user in nearly real-timé. In any event, a space station could support experiments involving ground-based user control of the sensors and processing equipment. The space station operator would serve as a backup in an experiment directed toward future automated and user-controlled data acquisition systems.

\section{Reducing Costs}

The concentration of machine and human resources at the point of data acquisition could reduce costs. Current approaches involve multiple processing, communications, and data distribution nodes. There are many people and systems in the data path that increase the final cost of the data. Data preparation, recording, mailing, and handling are expensive. If the data flows through a minimum number of nodes, cost minimization is possible. A manned space station offers this possibility. An interesting concept is the use of the space station as an orbiting archive, thus allowing a user to query and receive data directly from a large data base and eliminating conventional methods of physical data handling, such as shipping, inspection, receiving, etc. 
Orbit Considerations

Remote sensing satellites have been flown in the following types of orbits:

Near-polar, circular, sun-synchronous, low earth orbits near or below $1,000 \mathrm{~km}$ (exemplified by Nimbus, TIROS, Landsat, Seasat, and Defense Meteorological Satellite spacecraft)

Low-inclination, asynchronous, low earth orbits (exemplified by Shuttle and Explorer-type missions)

Geostationary orbits--either zero or very low inclination (exemplified by both communications and weather satellites primarily designed as operational-type missions)

Sun-synchronous, low earth orbits are most important to earth resources users. Landsat uses an orbit that provides synoptic coverage because the satellite overflys the same point on earth at the same time of day at 16- to 18-day intervals.

In summary, a near-polar, sun-synchronous orbit is essential for most remote sensing of the earth, but some sensors will have to be in geosynchronous orbit. Orbits giving skip coverage can better record episodic events, because the same general area is observed more frequently. Adjacent orbits are useful for mosaics and for signature extension (Landsats 1,2 , and 3 were in adjacent orbits; Landsat 4 is in a skip orbit, i.e., where successive meridional paths are separated by one frame-width). For most sensors, equator crossing times should be in daylight, but thermal infrared sensors may require night crossing times. Circular or near-circular orbits are essential.

THE ROLE OF MAN

The Panel can identify a number of roles for a human in space which may be grouped under the following headings: transient-phenomena identification; data-quality assurance; data processing, compression, and storage; experimentation; and repair, maintenance, and servicing. These roles are described in ensuing paragraphs. 


\section{Transient-Phenomena Identification}

Transient phenomena or episodic events such as hurricanes, volcanic activity, tornadoes, and floods cannot be predetermined as to precise time of occurrence or location, but a human in space could tell when a phenomenon was in progress or imminent, and could select the appropriate mode of data collection. For some events, the alerting of ground-based agencies could provide for better emergency planning. Direct notification of public communications channels as to the width, path, and direction of a natural disaster may help save lives and protect property.

\section{Data-Qua1ity Assurance}

Man could be used to monitor the quality of data collected in a space station. A human in space will be nearer to the sensors and therefore could more readily identify the source of any sensing or measuring problem and make the necessary correction. He could also control the instruments by changing bandwidth, response intensity, and fidelity range. Further and more rapid improvement of data quality could be achieved if a person is observing the instruments as they perform.

\section{Data Processing, Compression, and Storage}

As previously noted, a trained human operator in a space station could accept or reject data, decide to apply data-compression techniques, and decide whether to store data onboard or transmit it to the ground. All of these functions could result in a substantial reduction of the enormous volume of data that would otherwise be transmitted to earth and would have to be processed before its utility could be evaluated. The savings in data relay demands and data processing costs could be significant.

\section{Repair and Servicing}

The in-flight repair of Skylab not only saved the mission from a disaster, but also enabled the astronauts to complete most of the experimental objectives. Many of the solutions for failures or problems in a space station 
would likely be determined on the ground, but a human in space would be needed to make the actual repairs. When one considers the variety of instruments and sensors that could be used for remote sensing from space, the value of a human for in-situ repair and servicing becomes apparent.

\section{CONCLUSIONS}

The Panel has identified some of the potential benefits to be derived from a manned space station. The Panel has identified some roles for man, although we cannot justify a space station solely on the basis of earth resources applications.

A space station or unmanned platform would need to be in a low, near-polar, sun-synchronous orbit; some future provision should be made for a geostationary orbiting system. The sensor payload should be designed to operate interactively. Continuity of data should be assured and data formats should facilitate the integration of data from different sensor systems. 
EARTH'S ENVIRONMENT**

\section{INTRODUCTION}

The use of space vehicles as platforms from which to observe the earth's environment has led to a new perspective of our atmosphere. As a result of observations from space and other advances, significant progress has been made in our ability to observe and forecast changes in the earth's environment.

In preparing this report, the Panel examined the present state of scientific understanding in four major areas of interest--upper-atmospheric research, global chemical cycles, weather, and climate--for the purpose of defining requirements for future observational data. In each of these four areas, the Panel indicates the characteristics that would be needed in a space station or space platform to meet future data requirements.

Advances in technology that should be explored are identified at the end of each section. Orbit considerations and the role of man in space are discussed where appropriate.

ॠThe Panel acknowledges the assistance of many persons, especially Dixon Butler and Dudley McConnell of the National Aeronautics and Space Administration, James Purdom and Harold Yates of the National Oceanic and Atmospheric Administration, and Norman Phillips of the National Weather Service. 


\section{UPPER ATMOSPHERIC RESEARCH}

Introduction

A major use of space systems now and for the foreseeable future is to observe and measure the characteristics of the upper atmosphere (principally the stratosphere). The general state of understanding of this area has been recently reviewed in The Stratosphere 1981: Theory and Measurements (World Meteorological Organization, 1981).

During the past decade, the stratospheric ozone layer has become a focus of concern and a matter of regulatory activity. One concern is that humanly caused pollutants in the stratosphere could decrease the average amount of ozone, thereby admitting increased amounts of biologically harmful ultraviolet light to the surface of the earth. After atmospheric scientists predicted that chlorofluorocarbons diffuse to the stratosphere and contribute to ozone depletion, the Environmental. Protection Agency (EPA) regulated some uses of these substances.

A second area of concern arises from the fact that, in addition to screening out harmful radiation, the ozone layer plays a part in controlling the thermal structure of the stratosphere and mesosphere. Both dynamic and radiative mechanisms have been identified through which long-term changes in ozone could possibly affect weather patterns of the lower atmosphere--and hence climate.

Thus the study of the stratosphere has taken on a sense of urgency. There is need to predict reliably the impact of various substances generated by an industrial society on stratospheric chemistry.

What Is Required for Advancement?

Theory Needed

There is need for continued effort in atmospheric modeling. During recent years, one- and two-dimensional models--photochemical models with a highly parametric treatment of dynamics-have been developed and used to describe and forecast the state of the upper atmosphere. The chemical mechanisms incorporated in these models are reasonably realistic, although in many cases they have not been validated by comparisons with in-situ stratospheric 
measurements. Although these models may prove to be correct in certain types of calculations, their reliability in such applications may be demonstrated only after significant stratospheric changes have taken place. Therefore, an alternative approach is being used in which the simplified parameters used in the earlier models are replaced with explicit physical or chemical calculations. These new models operate in three dimensions, but still use primitive equations of dynamics, and have chemistry coupled to the dynamics as wel1.

Developing such a model is a difficult task. However, in a model with consistent calculations of the important processes, the validation of each process results in considerable confidence in the total model output; thus, these new models may achieve a level of credibility that will make them more useful than the older, simpler models. Hence arise the need for continuing vigorous effort on three-dimensional models and the challenging requirement to accumulate extensive global data sets, including simultaneous observations of stratospheric structure, motions, and composition.

\section{Laboratory Work Required}

The measurement of key chemical reaction rates and spectroscopic parameters in upper-atmospheric research has progressed we11. In the future, measurement of the variability of all relevant rate constants with temperature and pressure will be essential. Further, development and utilization of remote techniques for globally observing the upper atmosphere depend on measuring radiation or absorption by trace molecules (e.g. , $\mathrm{H}_{2} \mathrm{O}_{2}, \mathrm{ClO}$ and $\mathrm{NO}_{2}$ ); the determination of the spectroscopic parameters of such molecules represents another important area of laboratory research. Fina11y, there is a need for measurements of the kinetics of gas-to-particle conversion for several important gases found in the upper atmosphere.

\section{Needed Field Measurements}

There is need for simultaneous upper-atmospheric observations on a global scale. Important information on the presence and distribution of many substances in the 
upper atmosphere has been provided by measurements in addition to those from satellites. For example, balloon-borne sensors have confirmed the presence and measured the relative abundances of chemical species that interact with one another in the catalytic cycles governing ozone destruction (e.g., $\mathrm{NO}, \mathrm{NO}_{2}, \mathrm{OH}, \mathrm{Cl}, \mathrm{ClO}$, HC1). In addition, balloon flights have served as the principal means for developmental testing of upper-atmospheric remote sensors. Aircraft have provided valuable data on atmospheric dynamics, and in particular on exchange between the stratosphere and the troposphere.

Balloon flights and aircraft will continue to be needed as important sources of data for calibrating remote observations and for making detailed measurements that are beyond the present abilities of satellite remote sensors. However, it is only with simultaneous observations on a global scale that the complex interplay of chemistry and dynamics of the upper atmosphere can be truly studied. The only practical means of collecting this data set is by remote detection from space.

Research satellites have demonstrated that remote techniques can be used to observe some of the important species, such as $\mathrm{O}_{3}, \mathrm{NO}, \mathrm{NO}_{2}$, and $\mathrm{H}_{2} \mathrm{O}$, as well as aerosols. The next step in understanding the stratospheric ozone question requires simultaneous observations to check the completeness of the three-dimensional model and to validate the treatment of the interactions.

The required data set must include measurements of a larger list of key species $\left(\mathrm{HNO}_{3}, \mathrm{~N}_{2} \mathrm{O}, \mathrm{F}-11, \mathrm{~F}-12\right.$, $\mathrm{HC} 1, \mathrm{ClO}, \mathrm{H}_{2} \mathrm{O}_{2}, \mathrm{CH}_{4}$, in addition to $\mathrm{O}_{3}, \mathrm{~N}_{2}$, $\mathrm{NO}_{2}$, and $\left.\mathrm{H}_{2} \mathrm{O}\right)$, together with measurements of upper-atmospheric winds, stratospheric thermal structure, and solar output. NASA's planned Upper Atmosphere Research Satellite (UARS) is designed to make the needed atmospheric measurements. After UARS, the next major step needed is development of a system that will permit continuous data sets to be accumulated over a decade or more.

\section{Characteristics Required of a Space Station or a Space Platform}

There are several ways in which a space station or space platform could prove useful in achieving long-term upper-atmospheric measurements. One involves cooling 
systems. Should cooled sensors prove essential for long-term observations, on-orbit replenishment of cryogens may be imperative. On the other hand, active cooling systems may be more effective, even though they are heavy and high in energy consumption.

Another problem of long-term observations with any quantitative system would be the need to validate instrument calibration periodically. Direct access to the instruments would greatly improve the reliability and credibility of long-term observations. Repairing failed instruments on orbit would perhaps prove to be cost-effective, but further study would be required to establish this. All of these activities would require nove1 features in instrument design and an on-orbit infrastructure that would make them both possible and affordable.

Human presence on-orbit might prove cost-effective for servicing, replenishing, and calibrating. However, caution would be required in designing the human interface, since observations of the type described in this section would be quite sensitive to the chemical or particulate contamination and the vibration that would be associated with human presence.

Acquisition of the needed long-term global observations of the upper atmosphere may require a low earth orbit that provides limb-scanning coverage at various local times. There is also the possibility that the needed measurements would require a number of special-purpose remote sensors making simultaneous, collocated observations. Requirements of some or all sensors for a clear field of view could affect the size or configuration of a platform or a station used for upper-atmospheric observations.

\section{Technologies Needed}

Beyond those to be used on UARS, technologies needed in upper-atmospheric observations can be divided into three categories: remote sensing, data systems, and operational support.

Examples of remote sensing technology include the development of remote-measurement techniques for $\mathrm{OH}$ and $\mathrm{NO}_{2}$ and the measurement of $\mathrm{HCl}$ with better coverage (not using occultation). Various techniques, including lidar, need to be considered to make possible higher precision or higher resolution or new kinds of observations.

The capacity of data systems must be increased to handle the multiple-data-stream mode of operation that 
will be increasingly required if simultaneous measurements of a large number of species and parameters are to be made. The need for high-spectral-resolution measurements and the need to survey broad spectral regions to determine upper-atmospheric composition have the potential for creating large data streams consisting of new kinds of data (for example, complete interferograms). Data systems that included onboard processing might be essential in order for such devices to be used with maximum effectiveness.

Operational support technologies would be needed for the new generation of observations discussed here to become a reality. Larger space-borne power systems may be required by lidar instruments and stable, large structures would have to be developed to permit flying a large collection of sensors on one spacecraft.

\section{GLOBAL CHEMICAL CYCLES}

\section{Introduction}

This section focuses on the application of space systems to the study of the lower-atmospheric (i.e., tropospheric) portion of global chemical cycles. The preceding

discussion of upper-atmospheric chemistry is separate from this section on the troposphere only for convenience--these systems are in fact coupled, and research in the two areas needs to proceed in parallel.

Cycling of chemical species in the troposphere is frequently characterized by emission from the earth's surface of chemicals in partly oxidized states (e.g., $\mathrm{CH}_{4}, \mathrm{NH}_{3}, \mathrm{H}_{2} \mathrm{~S}$ ), transformation of these compounds by the atmospheric free radical $\mathrm{OH}$ to highly oxidized states (e.g., $\mathrm{CO}_{2}, \mathrm{HNO}_{3}, \mathrm{H}_{2} \mathrm{SO}_{4}$ ), and subsequent removal of the oxidized compounds from the atmosphere by rainout and washout. Global chemical cycles are closely coupled with the global hydrological cycle. Thus, complete understanding of global chemical cycles requires a corresponding understanding of hydrology as wel1 as of the chemistry of the air and the oceans.

Global chemical cycles affect many areas of human and environmental concern, including human health, agriculture, weather, and climate. Concerns range from global questions (e.g., Will increases in carbon dioxide 
in the upper atmosphere cause climate change?) to more localized problems (e.g., How does acid rain occur, and what are the most effective steps to reduce its occurrence and resulting damage?). A quantitative understanding of biogeochemical cycles and their time change will help to determine the impact of human activities on the biosphere and to prevent or ameliorate the unintended consequences of human activity.

What Is Required for Advancement?

\section{Theoretical Studies*}

Theoretical studies of global chemical cycles are an essential element of an effective research strategy. Tropospheric photochemical models for instance, have largely been responsible for delineating the central role of free radicals such as $\mathrm{OH}$ in the atmospheric chemical systems. A major goal for the future is to make these models chemically more sophisticated and dynamically more realistic. Studies are needed of the coupling of gas-phase atmospheric chemistry with cloud processes, including cloud microphysics, liquid-phase cloud chemistry, and cloud dynamics. The mechanisms that couple atmospheric chemistry with ocean and soil chemistry as well as with biospheric processes also need to be addressed. More sophisticated two- and three-dimensional models that simultaneously treat chemistry and atmospheric dynamics are needed.

\section{Laboratory Studies}

Laboratory studies to determine the kinetics of a wide variety of gas-phase, and aqueous-phase, reactions under atmospheric conditions have been and continue to be an important research area. One important example is the need to study the kinetic mechanisms that control the oxidation of gaseous $\mathrm{SO}_{2}$ to dissolved $\mathrm{SO}_{4}$ in a cloud.

\footnotetext{
*For a more detailed presentation, see Seinfeld and coauthors, 1981 .
} 
Field Measurements

Field measurements are required to develop a global chemical data base, to quantify the exchange rates of chemicals between the biosphere, atmosphere, 1ithosphere, and hydrosphere, and to test the accuracy of predictions using atmospheric photochemical models--such as predictions concerning the free radical oH. Such measurements--either ground-based, shipboard, or airborne--have already helped establish a rough understanding of the latitudinal and longitudinal distribution of many atmospheric species of interest (e.g., $\mathrm{O}_{3}, \mathrm{CO}, \mathrm{CH}_{4}, \mathrm{HNO}_{3}, \mathrm{SO}_{2}, \mathrm{CH}_{3}, \mathrm{CCl}_{3}$ ).

Unfortunately, our ability to use space technology to study atmospheric chemical composition is at present limited by the state of the art of remote sensing technology. Based upon recent reports (e.g., National Aeronautics and Space Administration, 1979; Keafer, 1982), it appears likely that by the 1990 s it will be possible to measure remotely from space only a small subset of the tropospheric species 1 isted above. This subset may include only $\mathrm{CO}, \mathrm{CH}_{4} \mathrm{O}_{3}, \mathrm{HNO}_{3}, \mathrm{H}_{2} \mathrm{O}, \mathrm{NO}_{2}, \mathrm{SO}_{2}$, $\mathrm{NH}_{3}$, and aerosols. Nevertheless, the ability to measure remotely even this limited set of atmospheric species could significantly enhance our global chemical data base. Thus, the Panel recommends that efforts be continued to develop tropospheric remote sensing technology; these efforts should include the use of the Space Shuttle to test each instrument under flight conditions. To calibrate the remote measurements, as well as to monitor those substances that can only be detected by sample analysis, a field measurement program using aircraft and ground-based observation platforms will be needed in conjunction with the development of the remote sensing technology.

\section{Possible Uses of a Space Platform or a Space Station}

Once a remote sensing technology for tropospheric chemical species has been successfully developed and tested, the instrumentation could be placed very usefully on a space platform. The advantages of a space platform would include: (1) the ability to have a large number of instruments on a single platform so that simultaneous measurements could be made of several atmospheric species and related meteorological parameters such as temperature, 
winds, cloud cover, and precipitation; (2) the ability to have a crew periodically visit, service, and calibrate the instrumentation, making it possible to obtain continuous data over a long time period and thus to study atmospheric temporal variability; and ( 3 ) the ability to use large, powerful, and heavy active sensors (such as lidar) to measure species that cannot be sensed by passive techniques.

For remote sensing of the lower atmosphere, a space platform should be placed preferably in a near-polar orbit that would afford complete global coverage. However, a high-inclination orbit $\left(\mathrm{e} . \mathrm{g} ., 57^{\circ}\right)$ would probably yield a large body of valuable information. Spacecraft in low-inclination low earth orbits would be useful for tropical measurements; however, the usefulness of a low-inclination orbit $\left(e_{. g},, 28.5^{\circ}\right)$ alone would be limited.

Beyond the 1990s, another very helpful configuration would be a series of platforms in various geosynchronous orbits that would permit study of the effects of episodic events (such as forest fires and rain systems) on chemical composition, and that would also allow for monitoring the dispersion of man-created emissions in the global atmosphere.

At this time, the Panel has identified only periodic maintenance and calibration tasks for which human presence in space would be helpful in the operation of remote sensors for environmental observations.

\section{Technologies Needed}

The greatest technological need in the study of tropospheric chemical cycles is the development of remote sensing technology. The current state of the art and likely near-future advances in this technology have been summarized in several recent reports (including Tropospheric Passive Remote Sensing [Keafer, 1982]; Shuttle Atmospheric Lidar Research Program [National Aeronautics and Space Administration, 1979]; and The Global Troposphere: Biogeochemical Cycles, Chemistry, and Remote Sensing [Levine and Allario, 1982]).

Based on these reports, the following list indicates the remote sensing techniques that presently look most promising for measuring data on global chemical cycles. 
Technique

Optical filter radiometer

Gas filter radiometer

Laser heterodyne

Orbiting spectrometer

Interferometer

Lidar

\section{To Measure}

Temperature, $\mathrm{H}_{2} \mathrm{O}, \mathrm{O}_{3}$, aerosols

$\mathrm{CO}, \mathrm{CH}_{4}$, and possibly $\mathrm{HNO}_{3}$, No, $\mathrm{H}_{2} \mathrm{CO}$

$\mathrm{H}_{2} \mathrm{O}, \mathrm{CH}_{4}$, and possibly $\mathrm{O}_{3}, \mathrm{HNO}_{3}$

Spectral survey

Spectral survey

$\mathrm{O}_{3}$, aerosols, temperature, winds, possibly $\mathrm{NO}_{2}$ and $\mathrm{SO}_{2}$

\section{WEATHER}

\section{Introduction}

For more than 100 years, the United States has operated an observing system for weather forecasting. Today this system includes data from passive radiation sensors on geostationary and polar-orbiting satellites. These satellite data include information on clouds (from visual and infrared images), on vertical profiles of temperatures and moisture (infrared supplemented by some microwave on the polar-orbiter spacecraft), and on sea surface temperature (infrared). Half-hourly cloud images from the geostationary satellites enable wind estimates to be made in those parts of the atmosphere where clearly identifiable cloud elements exist and are trackable from one image to the next.

Under the auspices of the World Meteorological Organization (WMO) and International Council of Scientific Unions (ICSU), the Global Atmospheric Research Program, culminating in the Global Weather Experiment in 1979, provided the framework for development and testing of global remote sensing techniques, for improvement of models, and for acquisition of the most advanced computer systems by meteorological research groups and weather 
services. The improved understanding and capability that resulted from these activities are increasing the ability to forecast large-scale features of the weather.

Forecasting for six to eight days is done routinely. A recent study by Lorenz (1983) concludes that further improvement of initial analyses (i.e., data) could extend this predictability limit to about two weeks.

On the nonsynoptic scale--the mesoscale and storm scale--there is neither the long history of continuous observations that exists on the synoptic scale, nor the ability to model realistically the complex and nonlinear processes that become more and more important as one moves to progressively smaller scales in the atmosphere.

This section discusses the possible roles for space stations or space platforms in producing further improvements in synoptic-scale forecasting and in undertaking the range of activities required to develop a national capability in mesoscale observing and forecasting.

What Is Required to Advance the Nation's Weather Services?

In the United States, there are needs for weather forecasts over a wide range of time and space--i.e., from minutes to weeks to climatic time scales, and from tornadic and airport-size to global scales. The needs include those of public safety (warnings of hazardous weather such as hurricanes, tornadoes, flash floods, and severe thunderstorms); those of various industries for weather information to aid the efficiency of their operations (e.g., air, land, and sea transportation; agriculture; construction; energy generation and use); the convenience of the public, which benefits in many ways from knowledge of anticipated changes in weather (especially temperature and precipitation); and the broad and complex needs of the Department of Defense for weather information that could affect military operations.

\section{Theoretical Advances Required}

Al1 forecast models, large-scale or sma11-scale, require some representation of the effect of motions on a scale too small to be represented explicitly in the model. The most important example of this "parameterization" problem concerns the effect of convective clouds. One cloud of 
this type can differ noticeably from another. Furthermore, the basic equation for cloud processes extends from the individual drops and ice particles to the larger-scale motion fields that may be concentrating the supply of water vapor in the convective region. Slow advances in solving this problem may be expected, especially from the detailed pictures of cloud motion that will be provided by new ground-based systems such as Doppler radar and wind profiler systems.

\section{Laboratory Advances Required}

In ground-based laboratory studies of weather phenomena, the primary needs are for studies of the microphysical processes that occur in clouds. Such studies will lead to a better understanding of heat release and formation of precipitation, which in turn will improve understanding of scale-to-scale interaction. Additionally, these studies will lead to improvement in the ability to measure remotely the relevant properties of clouds.

\section{Field Measurements}

Advancements in field measurements require a composite system that takes advantage of both space-borne and ground-based systems. For example, greatly inproved information on mesoscale atmospheric structure will become available through the integration of satellite cloud-type and sounding information with wind and sounding information from ground-based profilers. Automated surface observations in combination with Doppler radar and satellite data will improve our ability to diagnose severe and tornadic storms.

Ground-based profilers, Doppler radar, and automated data-collection platforms will have a major impact on weather research and services of the future. However, observational studies of cloud and precipitation processes are needed. These will require a combination of ground-based remote sensors and airborne in-situ remote sensors. 
Space-borne system advances needed in the field of weather can be divided into three aspects:

1. Increased accuracy and vertical resolution of satellite-measured profiles of temperature and moisture are needed. Present operational systems are not competitive with the conventional radiosonde, especially in the measurement of convective instability (the latent instability of the atmosphere in the presence of moist-air convection).

2. There should be a greater exploitation of microwave sensors, not only to provide temperature and water vapor measurements in cloudy areas, but also to increase the accuracy of measurements of precipitation and ground wetness from satellites.

3. Direct measurement of wind by satellite-borne Doppler lidar would greatly enhance the accuracy of large-scale meteorological analyses. In midlatitudes, winds are now derived by starting with infrared temperature profiles and then using the geostrophic assumption. In typical midlatitude situations, a temperature measurement with a $1^{\circ} \mathrm{C}$ error is easily matched in information content by a wind measurement with an error of $3.5 \mathrm{~m} / \mathrm{s}$ (Lorenz, 1983). But accuracies of $1^{\circ} \mathrm{C}$ or better are unlikely to be achieved operationally in the near future. On the other hand, Doppler lidar can measure winds directly with an error of $1 \mathrm{~m} / \mathrm{s}$ and hence would be much more valuable for wind measurement. At low latitudes, the temperature measurement error must decrease significantly to yield good wind information (see, for example, Phillips, 1983).

New and different sensing systems and spacecraft will be required to make the needed measurements. For example, a possible observing system might include the following:

- Spacecraft in high-inclination (polar) low earth orbit to provide data advanced over that provided by TIROS $N$ (one of the satellites in the National Weather Service operational system)

- Spacecraft in low-inclination (tropica1) low earth orbit especially for the measurement of winds and precipitation 
- Spacecraft in geostationary orbit carrying imaging and profiling systems using microwave channels as well as infrared, and thus providing profiling capabilities through clouds

Space platforms or space stations may be useful for some of these sensor systems, because they may require large amounts of power (more than $1 \mathrm{~kW}$ for a satellite-borne lidar designed to measure winds), their weight may be high, and they may need large antennas (for active or passive microwave sensors of adequate spatial resolution).

The operational payloads at low earth orbit and geosynchronous orbit that will be required to monitor the atmosphere adequately will be considerably larger and more expensive than existing systems. It seems probable, therefore, that if manned space stations were placed in low earth orbit for other purposes, it would be cost-effective to use the stations to update sensors or other system components, to repair and/or retrieve the payloads, and to construct larger structures for transfer to geostationary orbit.

\section{Technologies Needed}

Currently, in the lowest levels of the atmosphere over land, and in regions of clouds, satellite sounding systems are not able to define the three-dimensional fields of wind, temperature, and humidity with the accuracy desired for numerical weather prediction. Therefore, for the present, the satellite observing systems should be complemented over land by continuous, automatic, ground-based profiler systems, which are able to measure the desired fields in these regions with the necessary accuracy (Hogg and coauthors, 1983). In the future, an improved global wind-measuring system is needed to measure the tropospheric wind field. This is particularly necessary in the tropics, because in that region winds derived from temperature profiles are inaccurate and hence of little use. Infrared Doppler lidar offers a means of achieving a greatly improved wind-measuring system.

Improved microwave radiometry on low-earth-orbit satelites is needed to enhance satellite temperature and humidity profiling capabilities under cloudy conditions.

A method of measuring rainfall rate from satellites needs to be developed and tested. No generally accepted method of achieving this has yet been identified. 
A high-spatial-resolution microwave sounding and precipitation monitoring system needs to be developed for use on geostationary-orbit satellites. This will require a large microwave antenna system, for which some concepts already exist.

\section{CLIMATE}

\section{Introduction}

Climate is usually defined as the weather that occurs at a particular locale over an extended period of time. For the purposes of this report, a 30-day period is used as a lower limit to distinguish climate from weather.

The Sahelian drought and the oil embargoes of the 1970s focused worldwide attention on the effects of climate on our utilization of scarce resources. In 1979, recognizing the critical role of climate in societal and economic affairs, Congress enacted the National Climate Program Act. More recently, a World climate Program has been established jointly by the WMO, the ICSU, and the United Nations Environment Program (UNEP).

Improved forecasts of climate would permit more efficient use of scarce resources. For example, they would contribute to more effective planning of irrigation, more cost-effective distribution of fuels, and better management of commodity inventories.

Forecasting large-scale climate depends on progress in understanding a range of phenomena, such as stratospheric ozone, cloud/radiation processes, ocean temperature, ocean/air interface conditions, and ocean ice cover. Many studies of climate and of the advances required to predict it have been done by the National Research Council (U.S. Committee for the Global Atmospheric Research Program, 1975a,b) and others (Rasmusson and Carpenter, 1982; National Center for Atmospheric Research, 1980; and National Aeronautics and Space Administration, 1977). These studies led to the Panel's suggestions for field measurements.

\section{Field Measurements}

Requirements for field measurements are well defined by the U.S. National Climate Program Plan and by the World 
Climate Program mentioned above. Long-term (greater than 10 years), stable, reliable measurements are needed with high precision. In some cases, absolute accuracy is less important than are reliable measurements of trends, cycles, rates of change, or spatial gradients.

Measurements are needed for three reasons: (1) to monitor changing climate (what is happening); (2) to study ocean and atmospheric processes that affect climate (why climate changes); and ( 3 ) to guide and test climate model experiments (how climate might change in the future).

Advances in measurements for climate purposes are considered below for the following classes of observations: earth and solar radiation, internal atmospheric parameters (e.g., clouds, precipitation), ocean parameters (e.g., energy transport, biochemistry), ice and snow, and aerosols and gases. Ground-based and space-based contributions to the field measurements are discussed for each of these classes of observations.

Earth and solar radiation measurements are important in studying the energetics of the atmosphere. Net solar radiation has been found to correlate very closely with evaporation from $\mathrm{plants}$ and crops; reliable radiation data could improve crop models. However, radiation measurements are sparse over most of the continents and are essentially absent over the oceans.

Data sets of internal atmospheric processes for periods of time approaching 100 years are available from weather stations. However, these data sets are available only over land areas. Global data are needed.

Regarding oceanic data, in-situ measurements will be needed for subsurface currents, heat flux, salinity, and chemical composition for studies of global geochemical cycles.

For ice and snow, ground-based measurements will be needed for snow depth and snow-water equivalent. Passive and active systems are being investigated for deriving water-equivalent snow depth.

For gases and aerosols, ground-based measurements and aircraft and balloon measurements will continue to be needed for initial development of sensors and techniques and for verification of satellite measurements, as we 11 as to aid in fundamental research.

Earth and solar radiation measurements at the "top" and the "bottom" of the atmosphere are very important. On the 
climatic time scale, circulations in the oceans and the atmosphere are driven by thermal forces due primarily to radiation from the earth and the sun. At the top of the atmosphere, satellite measurements of the net energy exchange between earth and space and its variation are essential, and are being made.

Measurements by satellites of the solar energy output must be made by pointing at or tracking across the sun. Recent solar irradiance measurements from Nimbus 7 and from the Solar Maximum Mission spacecraft identified distinct episodic variations of solar output on scales of days; the variations are highly correlated with visible sunspots. The earth radiation budgets to be measured from satellites should place particular emphasis on the tropical regions (latitudes closer to the equator than $\left.30^{\circ}\right)$. The measurements are required at a resolution of 250 by $250 \mathrm{~km}$, with sampling several times per day. The radiation budget and climatological wind and precipitation requirements generate demands for data in the tropical regions and may make a low-inclination orbit useful.

For climate, certain satellite measurements (e.g., the Earth Radiation Budget Experiment [ERBE] and measurement of the sun's radiation in the Solar Maximum Mission) should be continued through the coming years.

In addition, the atmospheric parameters of winds, atmospheric moisture, and atmospheric temperature, in addition to clouds and precipitation, need to be measured from satellites. It is particularly important to obtain data on atmospheric precipitation patterns and cloudiness (VonderHaar and coauthors, 1982; National Center for Atmospheric Research, 1980; National Aeronautics and Space Administration, 1977), especially over ocean areas.

Understanding the influence of the oceans on climate is key to improving the entire state of knowledge regarding climate. Of special importance is the need to understand the transport of heat toward the poles and the influence on atmospheric dynamics of vertical exchange of heat and moisture at the air/sea interface. Finally, there is speculation that relationships exist between E1 Nino oceanic warmings, large-scale atmospheric dynamics (southern oscillation) and upper-atmospheric flow over North America (Rasmussen and Carpenter, 1982). The requirements for modeling and empirical studies are documented in several studies, such as the study of the 
National Center for Atmospheric Research (1980) and the Proposed NASA Contribution to the Climate Program

(National Aeronautics and Space Administration, 1977).

Major ocean climate experiments are being planned for the late 1980s through the 1990s. Space-borne measurements are expected to play major roles in covering the remote ocean areas. These experiments, if successful, are likely to lead to new and extensive ocean-monitoring requirements.

The earth's cryosphere is thought to be an interactive indicator of the earth's climate, but in order for the subject to be explored fully it is necessary to know the extent of continental snow cover, the extent of polar icepacks, and polar sea-ice concentrations. Because these areas are often heavily cloud-covered, microwave measurements that can penetrate the clouds are valuable. Even though snow and ice measurements so far have employed spatial resolution on the order of tens of kilometers, they have been useful for research and for some operational needs. Higher resolution is required, however, for future improvements in understanding--and perhaps monitoring--climate change.

\section{Possible Role of a Space Platform or a Space Station in $\mathrm{Cl}$ imate Research and Applications}

As noted earlier, a climate measurement program requires long-term, stable, and reliable measurements. A space platform implies a long-term effort and thus is consonant with climate objectives. Several possible uses of a platform for climate research and applications are specified below.

\section{Intersatellite Calibration Facility}

Because climate measurements require very careful attention to time and space sampling, systems of satellites are now being planned for climate purposes. The International Satellite Cloud Climatology Project (gathering data from 1983 through 1987) proposes to use six satellites ( $f$ ive geostationary, one sun synchronous) to obtain required information about clouds. During 1984 through 1986, two or three satellites (one with a $57^{\circ}$ orbit and the others sun synchronous) are planned to be used in the ERBE project to measure the energy exchange between earth and space and to monitor direct solar energy 
output. Such systems of satellites are essential to meet climate (and some weather) requirements. Of ten such satellite systems may include some non-U.S. satellites. In such cases, there is a special need for each satellite system to be normalized so that calibration shifts of individual sensors, should they occur, do not invalidate the overall system. A sensor package on board a space station would serve as an excellent calibration standard because it could be routinely tested in space or even returned to earth if necessary.

The sensors' footprints on the earth would have to be matched, and a space platform (for example, on an orbit inclined at $28.5^{\circ}$ ) would have to underfly free-flying satellites in the system to permit intercalibration at each encounter.

Low Signa1-Above-Background Measurement

Some climate-related measurements, such as those for very detailed winds, certain volcanic gases and aerosols, and low-level moisture, have a very low signal-abovebackground level. To detect these fine-scale, yet important, climate features, special instruments (e.g., lidars) may be needed. Power and other requirements for these sensors may preclude their use on a free-flyer, which would perhaps be too small to support such sensors; thus, a space platform may be the optimum satellite for this purpose. Normally, global coverage would be required for climate modeling and monitoring. However, certain important parameters such as tropical winds could be measured from a low-inclination platform.

\section{Assembly of Large Antennas}

Climate research could benefit from higher-resolution microwave measurements. This will call for the deployment in space of antennas with diameters up to $10 \mathrm{~m}$ in low earth orbit, and much larger in geostationary orbit.

Role of Man in Space

for Climate Research and Applications

In general, the Panel finds no requirements for human observers in space for climate research or for 
applications of climate-related remote sensing. If a manned observatory is planned for solar physics studies, certain climate-related measurements of total and spectral energy from the sun might be included. Of course, the accuracy and precision of the measurements would have to match or exceed those from unmanned sites.

\section{CONCLUSIONS}

The Pane 1 has focused on possible evolutions in environmental observations during the 1980 s and examined the role that a space platform or a space station might play in future developments.

It is generally concluded that a space station offers the potential for several new activities in space, inc lud ing :

Combining a large number of sensors for simultaneous observation of many species in the atmosphere

The ability to recalibrate instruments frequently and to use these instruments to intercalibrate satellites

The possibility of refurbishing and repairing instruments and of maintaining cooled detectors for an extended period

The introduction of new facilities such as lidar or major microwave observatories in space

Advances in technology that should be explored are:

Development of remote-measurement techniques for $\mathrm{OH}$ and $\mathrm{NO}_{2}$

Techniques for handling a multiple-data-stream mode, including onboard processing

Larger space-borne power systems

Development of tropospheric remote sensing instruments

Development of a global wind-measuring system

Improved microwave radiometry for low-earth-orbit satellites

Development of a method for measuring rainfall from satellites

Development of a high-spatial-resolution microwave sounding system 
In regard to orbit, while low-inclination low earth orbits are useful, especially for observing tropical weather and climate, by far the most important orbits for environmental observations are low-altitude near-polar orbits (for rapid-response, synoptic weather forecasting) and geostationary orbits (for environmental observations and for atmospheric sounding). If a space platform having a number of sensors is contemplated, it should be placed in a low-altitude near-polar orbit.

The general conclusion regarding the role of man in space is that human presence could be useful on a periodic rather than on a continuous basis. This conclusion, by necessity, is based on a limited examination. The possibilities of a more creative and innovative role for man in space should be examined in more depth.

\section{REFERENCES}

Hogg, D. C., M. T. Decker, F. O. Guiraud, K. B. Earnshaw, D. A.Merritt, K. P. Moran, W. B. Sweezy, R. G. Strauch, E. R. Westwater, C. G. Little. 1983. An automatic profiler of the temperature, wind and humidity in the troposphere. Journal of Climate and Applied Meteorology 22(5):807-831.

Keafer, L. S., Jr., ed. 1982. Tropospheric Passive Remote Sensing. Proceedings of a workshop held July 20-23, 1981. NASA Conference Publication 2237. Accession No. 82N-26637. Springfie1d, Va.: National Technical Information Service.

Levine, J. S., and F. Allario. 1982. The global troposphere: biogeochemical cycles, chemistry, and remote sensing. Pp. 263-306 in Environmental Monitoring and Assessment, Vol. 1. Dordrecht, Holland/Boston, Mass.: D. Reidel.

Lorenz, E. 1983. Atmospheric prediction experiments with a large numerical mode1. Tel1us 34:505-517.

National Aeronautics and Space Administration. 1979. Shuttle Atmospheric Lidar Research Program. NASA Special Publication 433. Washington, D.C. 
National Aeronautics and Space Administration. 1977. Proposed NASA Contribution to the Climate Program. Greenbelt, Md.: Goddard Space Flight Center.

National Center for Atmospheric Research. 1980. Space-Based Observations in the 1980 s and 1990 s for Climate Research: A Planning Strategy. Boulder, Co10.: Committee on Space Research, International Council of Scientific Unions.

Phillips, N. 1983. An accuracy goal for a comprehensive satellite wind measuring system. Monthly Weather Review 111:237-239.

Rasmusson, E. M., and T. H. Carpenter. 1982. Variations in tropical sea surface temperature and surface wind fields associated with the southern oscillation/E1 Nino. Month1y Weather Review 110(5):354-384.

Seinfeld, J. H., F. Allario, W. R. Bandeen, W. L. Chameides, D. D. Davis, E. D. Hinkley, R。W. Stewart. 1981. Report of the NASA Working Group on Tropospheric Program Planning. NASA Reference Publication 1062. Hampton, Va.: Langley Research Center.

U.S. Committee for the Global Atmospheric Research Program. 1975a. Elements of the Research Strategy for the United States Climate Program. Washington, D.C.: National Academy of Sciences.

U.S. Committee for the Global Atmospheric Research Program. 1975b. Understanding Climatic Change: A Program for Action. Washington D.C.: National Academy of Sciences.

VonderHaar, T., S. Cox, T. McKee, and E. Raschke. 1982. The Space-borne Global Climate Observing System. Final report on contract NAS 5-26343. Greenbe1t, Md.: Goddard Space Flight Center.

World Meteorological Organization. 1981. The Stratosphere 1981: Theory and Measurements. Report No. 11, WMO Case Postale No. 5, Global Ozone Research and Monitoring Project. Geneva, Switzerland. 


\section{OCEAN OPERATIONS*}

\section{INTRODUCTION}

As a result of recent economic, political and scientific developments, the world has entered a period of increasing interest in ocean operations. Some of the factors accounting for this new interest are the establishment of national economic zones extending 200 nautical miles from the shorelines of coastal nations, growth in size and number of oceangoing ships, movement of petroleum exploration into the offshore regions of as many as 50 nations (in addition to the 50 countries that had offshore oil wells in 1979), increasing importance of worldwide fishing, prospects for ocean-bed mining, concern about protecting the ocean from dumping of toxic wastes, the promise of power generation from ocean waves and thermal differentials, and the expansion of naval defense activities. These developments result in growing needs, among government and private concerns having oceanic responsibilities or interests, for ocean data. This chapter addresses space systems as they might be used for obtaining oceanic data to meet the needs of the user community. This chapter deals principally with the use of remote sensing from space in ocean operations. We recognize that navigation satellites are becoming important in ocean operations, and this subject is treated briefly in the next chapter (Satellite Communications).

*The Panel acknowledges the valuable contributions made by John W. Sherman III of the National Oceanic and Atmospheric Administration. 
From a physical standpoint, the world's oceans cover more than two-thirds of the surface of the earth, occupying more than 350 million square kilometers, and having a volume of nearly 1.5 billion cubic kilometers. Approximately 5 to 8 percent of the oceans are covered by ice. The oceans support a multitude of physical, biological, and chemical processes, and constitute vital national and international resources.

In considering the utility of satellite remote sensing to the oceanic community, two factors need to be taken into account: from the scientific viewpoint, major ocean basins behave as entities; from the political viewpoint, the developing body of international sea law will eventually have an important impact on various ocean activities.

The concept of the oceans as entities drives many of the requirements for synoptic coverage by satelites. For the purposes of oceanography, the earth may be considered to be divided into halves--north and south--at the meteorological equator, which generally lies north of the geodetic equator. The oceans behave as entities because the gross water circulation of each of the major ocean basins of the world--i.e., the North Atlantic, South Atlantic, North Pacific, South Pacific, and Indian oceans--is largely self-contained; the circulation in each basin is rotary in the upper layers, with little exchange of water between the two hemispheres. Some of the the polar regions are ice-covered much of the year and behave to a large extent as separate oceanic areas. They do, however, interact with lower-latitude seas, and it is the marginal areas of the polar regions that are the most environmentally active.

The surface circulation of the ocean basins is a major mechanism for global dispersal of incoming solar heat, initially collected in low latitudes. Because of the nature of the flow within basins, problems of water circulation must be considered on an oceanic scale, taking in the far northern and southern extremes of the major basins. Thus, two distinct areas are of concern to oceanographers: the major ocean basins over their full latitudinal extent, and the polar areas. In dealing with oceanic-scale problems, then, minor increases in latitudinal coverage are of small value until the final increment--which includes the basin margin--is reached.

The development of a new body of international sea law may have strong implications in many fields of oceanic endeavor. National sovereignty over activities in and on 
the sea now extends 200 nautical miles offshore. Some measure of international control on the remainder of the oceans can also be anticipated--the recent Law of the Sea Treaty, for example, provides for control over ocean-bed resources. The establishment of the 200 -mile national boundary greatly inhibits access of fishermen and scientists to the coastal waters of other nations. The effect is to drive both groups farther out onto the high seas--outside the current jurisdiction of coastal nations. As restrictions are placed on fishing and research ship activity, it must be expected that needs for satellite-based navigation and communications services will increase, and remotely sensed data in the coastal regions will become more important.

The Panel concludes that to be of significant value, observations from space must cover the major oceans and require spacecraft in polar or nearly polar orbit. Conversely, observations from spacecraft on orbits having inclinations in the range of $25^{\circ}$ to $35^{\circ}$ can contribute relatively little additional insight into problems related to oceans as entities, nor can they meet the increased need for navigation and communication services.

\section{CURRENT STATUS OF REMOTE SENSING OF THE OCEANS}

The areas in which ocean data are useful are diverse, and reponsibilities for the oceans and activities in or upon them is dispersed among many agencies, organizations, and individuals. In the federal government alone, such agencies as the departments of State, Defense, Transportation (Coast Guard), and Energy, the Environmental Protection Agency (EPA), the Nationa1 Aeronautics and Space Administration (NASA), the National Oceanic and Atmospheric Administration (NOAA), and the National Science Foundation (NSF) need or acquire ocean data. Many state and local government agencies can be added to the list. In the private sector, organizations using ocean data include such enterprises as shipping concerns, fisheries, oil and gas producers, and several international consortia formed for ocean mining. Individuals who use ocean data include commercial fishermen and marine scientists. 


\section{Ocean Observations from Aircraft}

Ocean data obtained by observations from aircraft provide an overview of ocean surface conditions that is of importance in research. Aircraft using air-dropped buoys can obtain data in remote areas and over wide expanses of ocean on a near real-time basis. Below are some examples of research and operational uses by the U.S. Coast Guard, NASA, NOAA, and the Navy of ocean observations obtained from aircraft.

The Coast Guard uses information obtained from aircraft in its search and rescue operations as well as in its efforts to patrol the 200-mile economic zone. In addition, the Coast Guard uses such data in oceanographic surveys, ice patrols, and oil-spill responses. Also, airplanes equipped with radar, infrared sensors, and optical cameras are used for oil-spill surveillance.

NASA has used aircraft such as the high altitude TR-1, the $\mathrm{C}-130$, and the $\mathrm{C}-54$ in experiments to remotely sense the oceans for sediment transport, marine pollution, phytoplankton dynamics, sea ice, and ocean dumping and other activities.

NOAA's National Marine Fisheries Service (NMFS) charters airplanes from private companies to observe the 200-mile economic zone, primarily to support the Coast Guard in the control of foreign and domestic fishing activities. NMFS has used aircraft-mounted television cameras to search for schools of menhaden, an economically important fish abundant along the U.S. At lantic coast. Also, NOAA conducts a variety of ocean observations as part of its environmental research program, and the National Weather Service uses "hurricane hunter" aircraft to obtain data for hurricane reconnaissance.

The Navy uses aircraft to conduct acoustic, sea ice, and magnetic experiments in a wide range of programs.

\section{Ocean Observations from Satellites}

Oceanic measurements from satel1ites began in the 1960 s with spacecraft such as NASA's Nimbus series of experimental satellites, NOAA's TIROS and improved TIROS series of global weather satellites, and the Defense Meteorological Satellite series (DMSP): Although some oceanographic data were produced by these spacecraft, 
providing data to the ocean community was not their primary mission, and the data were more a matter of curiosity than of use to those who had access.

Experiments specifically for oceanography began with a microwave experiment package aboard Skylab* in 1973. The package included an altimeter, a scatterometer, and a radiometer. Another ocean altimetry experiment followed on GEOS-3 (Geodetic and Oceanographic Satellite) in 1975. In 1978, Seasat--a "proof of concept" satellite dedicated to oceanography--carried an array of sensors. The mission was cut short by a power failure after three and one half months. Seasat provided excellent data for the research community, and its measurements met their technical objectives. Seasat's brief lifetime, however, did not permit accomplishing planned experiments in operational use of the data, such as optimum ship routing forecasts.

With the demise of Seasat, oceanographers turned to other satellites for whatever data could be obtained. Although oceanographic data have been obtained from a variety of sensors on other satellites (Nimbus 7, GEOS, etc.), the data as a whole do not meet the requirements for research or operations. Ocean operations and research need 24-hour global coverage, sea surface observations by several instruments, and the ability to obtain repeat coverage, at least once a day. The Panel is in agreement with the observations of the Space Science Board's Committee on Earth Sciences that "in the area of ocean dynamics, space techniques offer the only practical means to determine the surface boundary conditions for general circulation of the ocean" (Committee on Earth Sciences, 1982).

A National Oceanic Satellite System (NOSS), a proposed cooperative program among NOAA, the Department of Defense, and NASA, would have filled many requirements for oceanic operations. As originally conceived, NOSS was a two-satellite program using proven sensors for operational data and research. The system was designed to operate for five years (until about 1991), and it was hoped that a fully operational system would follow. NOSS was cancelled in 1981 .

NASA's plans still include an ocean satellite, the Dynamic Topographic Experiment (TOPEX). Its mission is to

* Skylab was a NASA spacecraft that supported three-man crews in orbit for up to three months. 
obtain ocean topography accurate to $2 \mathrm{~cm}$, averaged over 4 $\mathrm{km}$ on the ocean surface. In addition, as a low-cost alternative to NOSS, NASA is examining the possibility of flying, as piggyback payloads on various spacecraft, individual instruments such as a scatterometer and an ocean color sensor. Also, NASA has agreed to perform with Canada's Division of Energy, Mines and Resources a bilateral study of the requirements for a future satellite having a synthetic-aperture radar as its principal instrument--the RADARSAT-FIREX mission study.

The Navy, with the Defense Mapping Agency, is developing a small satellite to acquire geodetic data, filling a void left by the failure of Seasat. The Navy updated its operational needs for ocean data, and has proposed a navy remote ocean sensing satellite system (NROSS).

Finally, other nations of the world are developing ocean-data satellites. Japan's National Space Development Agency has scheduled launch of a maritime observation satellite in 1986, and the European Space Agency has completed preliminary design studies of a remote sensing satellite system, tentatively scheduled for launch in 1987 .

THE NEED FOR OCEAN DATA--MAJOR USES

This section is a discussion of functional areas for which ocean data are needed, indicating where the data could be provided by remote sensing from satellites. The areas discussed are protection and control of economic zones; coastal preservation; fisheries development; offshore oil and gas exploration, drilling, and production; mineral extraction; power generation; ocean pollution; sea ice monitoring; ocean research; and naval activities.

\section{Protection and Control of Economic Zones}

Today, among many nations there is acceptance of a functional economic zone extending 200 nautical miles offshore. One section of the Law of the Sea Treaty, mentioned earlier, will give coastal nations control of their adjacent waters to 200 miles offshore. This authority implies responsibilities, such as protecting resources, monitoring traffic, and providing maritime assistance. Also, it may imply the eventual authority to control tens of thousands of oceangoing ships, just as 
air traffic has been controlled, worldwide, for decades. Policing the 200-mile economic zone in the United States has challenged the Coast Guard, which faces constantly rising costs of ship operations and the diminishing size of its operational fleet. Routine surveillence of large ocean areas by remote sensing would make it possible to use Coast Guard vessels for direct action when specifically needed, and thus to operate more efficiently.

The ability of satellite sensors to detect, track, and monitor activities of oceangoing ships is wel1

demonstrated. Therefore, the Panel recommends development of this capability for effective surveillance, control, and management of maritime activities in the offshore economic zone of the United States.

\section{Coastal Preservation}

Coastal zones are subject to atmospheric, oceanic, and alluvial influences. These influences affect

habitability, suitability for construction, and industrial and military operations on and near shore. Remote sensing can complement in-situ measurements of factors that affect the coastal zones and can detect alluvial sand deposition, flooding, and beach erosion. In addition, wave height and shallow bathymetric measurements would further increase the use of remotely sensed data by those concerned with the protection of the coastal zone.

\section{Fisheries Development}

In commercial ocean fisheries, remotely sensed data is of principal use in operations concerned with stock harvesting and stock management. For stock harvesting, fishermen need an a11-weather observing system (for navigation, hazardous warnings, etc.); sea surface temperature estimates (for locating preferred fish habitats); and ocean color monitoring (for determining the presence of plankton). For stock management, scientists need ocean color monitoring (for detection of chlorophyll concentrations); surface wind measurements (for estimation of surface-water transport); and a detection and tracking capability (for determining the size of schools of pelagic fish and for tracking sea mammals).

Remotely sensed data are being used today by commercial fisherman and fishery scientists. However, major 
improvements are needed to meet the needs of this community. Most important are a system for hazardous warning; sea surface temperature estimates; an ocean color monitoring capability; a detection and tracking capability; and better estimates of wave height, rainfall, and wind speed and direction.

For fishing activities, the most important areas are in the 200-mile economic zone. However, some fishing occurs on the high seas, which requires coverage over a wide range of latitudes, from the equator to polar waters. Thus, a near-polar orbit would be necessary to benefit fishing activities.

Offshore Oil and Gas Exploration, Drilling, and Production

Today there are approximately 25,000 petroleum wells in offshore areas of the United States producing about 12 percent of U.S. oil and 27 percent of U.S. gas. In addition, offshore oil wells in 50 countries provide 20 percent of the world's oil production. Fifty more countries have offered offshore sites for petroleum exploration. Many experts in the oil industry, government, and academia believe that in the decades ahead the remaining onshore resources will decline in importance while yet-unexplored offshore areas, involving more hostile environments, more remote locations, and deeper water, will increase in importance.

offshore petroleum activities involve three distinct phases: exploration, drilling, and production. Each phase has unique needs for data and information. Exploration is usually done by specialized research ships. While they are somewhat more weather sensitive than are cargo vessels, their needs for forecasts are similar to those of other surface ships and they can usually avoid adverse weather. Offshore drilling operations are carried out from bottom-mounted platforms or from mobile ships or submersible platforms. While drilling is in progress, an active connection extends from the mobile or fixed unit into the seabed, so that evasion of bad weather is difficult for mobile platforms and impossible for fixed platforms. Accurate advance information on weather and waves--especially on potentially severe conditions--is required. In the production phase, when hydrocarbons flow via seabed pipelines to the shore, sensitivity to environmental conditions is somewhat less, but reliable 
forecasts are still needed. Improvements in weather and ocean observations by remote sensing from space, accompanied by improvements in weather models, could produce a forecasting system that would meet the needs of oil and gas companies.

\section{Minera1 Extraction}

Although some mines near coastlines have shafts extending into underwater areas, the term "ocean mining" refers to the collection and processing of nodules that are found on the ocean floor. Rich in various metals such as manganese, copper, and nickel, these nodules hold the promise of a substantial mineral harvest. The technologies needed to gather and process the nodules are in hand: several international consortia have been formed for extensive ocean-mining operations. U.S. companies planning deep-ocean mining face considerable uncertainty because of legal, economic, and political circumstances. Nevertheless, data on ocean weather, waves, and currents will be of great importance to any ocean-mining operation.

\section{Power Generation}

Certain natural phenomena in the oceans--temperature gradients, wave action, and salinity gradients--hold promise for generation of electrical energy. Ocean thermal energy conversion and power generation from wave action have been demonstrated and await favorable economic conditions in order to proceed. With the costs of electrical energy continually escalating, the Panel believes that these techniques will be required during the period considered in this study (to the year 2000). To support offshore power generation, as well as power stations built near coastlines, ocean data are needed for site selection, assessment of pollutant transport, environmental protection, design of thermal and wave action systems, and monitoring of physical, chemical, and biological conditions. Satellite observations seem to be the logical choice for meeting this demand. 


\section{Ocean Pollution}

In recent years, the ocean has become a dumping ground for outmoded ships, radioactive materials, chemicals, and other pollutants. Pollution from shipping and offshore oil wells, and effluents from onshore power stations and whole cities, are endangering the ocean environment-especially in coastal areas. With commercial activities continuing to increase, the threat to the quality of the ocean environment will rise.

Monitoring ocean pollution requires observations of ship traffic and observation of the effects of pollution on the water. The first function could become a special task within a general program of monitoring ocean traffic by satellite observations--a service that may well develop for other reasons, such as control of fisheries and direction of ship traffic. The second function is more complex in that some factors, such as oil spills or particulate matter, can be observed with current techniques while other, more subtle changes, such as the effluent from a chemical plant, are beyond the present capabilities of remote sensing. The need for development of these techniques is suggested in the section "Future Needs." However, only satellites can fill the need for monitoring the oceans on a synoptic scale.

\section{Sea Ice Monitoring}

The earth is a heat engine; energy from the sun is received in the tropics and lost from the polar regions. Sea ice in the Arctic and Antarctic is a result of that heat loss. Where sea ice meets warm water, it melts at an unsteady boundary. The extent of ice varies with the seasons, with a six-month phase difference between north and south latitudes. For reasons that are not yet understood, ice extent varies from one year to the next. The shipping industry, fishermen, and others operating in polar regions refer to "good ice" years and "bad ice" years. Bad ice is a lot of ice getting in one's way, and good ice is the lack of the same. Clouds and fog are frequent where ice drifts; hence, detection and tracking of this potential hazard should be done by microwave sensors, such as Seasat's synthetic-aperture radar.

The global demand for fossil fuel has led to increased activity in the Arctic, accompanied by a need for more and better information on the extent and motion of sea 
ice--particularly where the ice is thicker. Thick ice presents a hazard to shipping, to offshore installations, and to structures onshore as well. Thin ice, while not as hazardous, can be a problem for fishermen. Because thin ice comprises most of the vast area of annual fluctuation, it is of interest to scientists. In drifting ice, leads (channels of water through ice fields) can open and close in hours or even minutes, so that forecasters, ship operators, and others need frequent coverage. Sea ice monitoring is another area where satellites can play an increased role. The use of sensors operating at several frequencies would help remedy the problem of determining sea ice thickness by remote sensing.

\section{Ocean Research and Science}

of the four major disciplines in ocean research--physical oceanography, biology, chemistry, and geology--physical oceanography has benefited most from remote sensing, because the ocean is most active in its upper layers, where phenomena of interest can be observed. Biologists have also benefited, since oceanic life is concentrated near the surface. However, chemists and geologists have been able to make little use of remotely sensed data, because few chemical factors and almost no geological phenomena are observable by remote sensing. The Panel believes that this situation is not likely to change.

For ocean research, remote sensing holds some important advantages over conventional shipboard sampling. Research vessels are limited to advancing a hundred or so miles per day, and are further limited to local observations. On the other hand, satellites can scan a very large area at a rate that is fast compared with the rate of most oceanic processes. Thus, remote sensing can provide amounts of data many orders of magnitude larger than those from a fleet of research ships. Nevertheless, in those disciplines that can benefit from the use of remote sensing data, far less than full use has been achieved because of the problems of handling large masses of data and a lack of confidence in the validity of the data (due in part to inadequate ground-truth validation). Broad professional acceptance may well have to await the arrival of a new generation of oceanographers, who will have grown up with remotely sensed data, just as they have grown up with computers. 
In addition, many persons in government agencies that provide financial support for oceanic research share the skepticism of some scientists about remotely sensed data. For years, they have supported research done from a ship by a professor, some students, and a few technicians. One short cruise every year or so has provided data adequate for several years of study. To process and analyze the flood of information from a satellite requires different talents and more people. Sponsors of scientific research are often not geared conceptually or financially to deal with this problem. The result is a self-perpetuating conservatism, and as a consequence valuable data are being neglected. The Panel believes that sponsoring agencies should be alert to novel approaches in ocean research and should be prepared to support them. On the other hand, the remote sensing community must become more sensitive to the data and information needs of ocean scientists and ocean operators.

\section{Naval Activities}

Most naval operations, as well as the logistics system that support them, can benefit from timely receipt of suitable ocean data. The Navy has established an operational requirement for satellite measurement of oceanographic data (SMOP OR-W0527-OS), which specifies the horizontal resolution, precision, and accuracy of oceanic measurement needed for naval operations. In addition, the Navy is developing a system for delivery of this data to fleet units and command centers. The system will use data from several satellites, merge the data in processing operations, and disseminate the data in processed form.

\section{REQUIREMENTS FOR SPACECRAFT FOR OCEANIC REMOTE SENSING}

This section identifies technological requirements for a space station or space platform with oceanic remote sensing capability. Preceding that discussion is the Panel's evaluation of the Space Shuttle as a system for delivering ocean survey satellites to orbit and as a test bed for sensors designed for ocean observations. 
The Space Shuttle as Delivery System and Test Bed

As a delivery system, the Space Shuttle is quite compatible with requirements for ocean-data-gathering space systems, which might involve delivering a free-flying ocean satellite into orbit, carrying pallet-mounted instruments, or transporting modules to be incorporated into a space station or space platform. In studies of the National Oceanic Satellite System by NASA, the Department of Defense, NOAA, and three systems contractors, the ability to package the key ocean-data sensors on a free-flying satellite, which could be delivered to orbit by the Shuttle and retrieved by the Shuttle for refurbishment or repair, was well established.

In addition to its capabilities as a delivery system, the Space Shuttle has proven itself to be an effective test bed. While still in its R\&D phase, the Shuttle carried payloads of experiments as secondary missions. A pallet aboard the second Shuttle carried experiments for NASA's applications program. Though the instruments were operated only for a limited time, the results were useful. The Panel concludes that the Shuttle will be useful both as a delivery system for satellites with oceanic remote sensing capability and as an orbiting test bed, carrying experimental ocean-data-gathering instruments.

Free-Flying Observatories with Space Station Support

Orbit requirements and other limitations may make it impractical to use a space station or space platform to carry ocean-monitoring instruments. In such cases the instruments might be placed on free-flying spacecraft, which could be located within range of astronauts from a space station, or could receive communications, power, or other support from the space station. Personnel on board a station might be able to repair the free-flyer or to replace parts. If power could be transmitted from a central power source, power-generating equipment on board the free-flying spacecraft could be minimized. Operational control of free-flyers from a station and use of a station to relay data to the ground could simplify the design of ocean-monitoring satellites.

The Panel concludes that free-flying observatories would benefit from services that might be provided by a 
space station, and recomends that these possibilities be examined during future planning for a space station.

\section{Some Key Factors}

The Pane 1 was able to establish some requirements for a space station or platform in order for it to be useful for acquiring ocean data. Three key factors--instruments, data handling, and orbit selection--will determine whether a space station or platform can efficiently provide ocean remote sensing data. A discussion of these factors follows.

\section{Instruments}

The types and numbers of sensors that have been used or are planned for measuring ocean data are as follows:

Visible light sensors--five in use and four planned Infrared radiometers--eleven in use and two planned Passive microwave sensors--four in use and two planned

Active microwave sensors and lasers--four in use and three planned

The Panel concludes that sensor technology has progressed to the point where the most important ocean measurements can be obtained with available sensors.

To obtain the important ocean data, a variety of sensors should be used. For example, instruments operating in the visible or infrared bands provide measurements with high spatial resolution but cannot "see" through clouds, whereas microwave instruments can see through clouds or darkness but have poor spatial resolution.

Also, since the antennas for microwave instruments must be large to provide adequate spatial resolution, interference with instruments while in orbit may be a problem.

In the future, it may become desirable to use new sensors--for example, sensors that can measure ocean depths, carbon dioxide, surface chemical factors, or salinity. Some sensors, such as synthetic-aperture radars (SAR), provide data from which a variety of phenomena can be derived. A SAR was flown on Seasat with good results and on the OSTA-1 pallet payload on the second Space 
Shuttle. Microwave sensors can provide wind, wave, ice, and sea surface temperature data, which are needed by many users. Ocean color data, needed by fisheries and pollution specialists, can be obtained with instruments like the Coastal Zone Color Scanner carried on Nimbus 7.

\section{Data Handling}

If a full complement of ocean sensors is operated on a full-time duty cycle, one can foresee a requirement to transmit up to one gigabit (one billion bits) per second. This would appear to be a maximum requirement for ocean operations. On-board data processing or reducing the duty cycles of the instruments could relieve the demand on the data communication system.

If humans are to aid effectively in observing the oceans from space, they will need tools to process and reduce data collected by onboard sensors. An image processing and display capability on board the space station would permit interactive information manipulation and analysis, and thus make it possible to reduce data transmission requirements. Without such capability, the human role would be limited to instrument tending.

Many users are not equipped to handle large quantities of data or data that must be processed to yield useful information. Many research ships are not equipped for large-volume data exchange, nor do they have computer facilities and peripherals necessary to assimilate it. Industrial users such as fishermen are even less adequately equipped. Instead of data, they need useful information, such as the coordinates for points where fish are to be found. Most users, in fact, would prefer that the conversion of data to useful information be done by someone else--at no cost to the user. Obviously, the interface between the generators of large quantities of raw data and the potential customers has not been adequately addressed. In some respects, lukewarm consumer support has been due to a lack of appropriate packaging and marketing. The Panel believes that for remote sensing from space to achieve its potential utility, data products will have to be made readily usable for prospective users.

\section{Orbit Selection}

Ocean users need global coverage, with observations day and night under all weather conditions. A high-inclination, 
sun-synchronous orbit--i.e., an orbit with an inclination of approximately $98^{\circ}$, at an altitude of about 400 nautical miles--will satisfy most users. For some special uses, other orbits may be needed, but even these cases will require relatively high-inclination orbits--for example, at least $62^{\circ}$ for TOPEX and $108^{\circ}$ for the Navy's geodetic satellite.

The Panel concludes that high-inclination orbits are needed to observe whole ocean basins; low-inclination orbits- $-25^{\circ}$ to $35^{\circ}$, for example--will be only marginally useful.

\section{FUTURE NEEDS}

\section{Advances in Direct Measurements and in Monitoring Scope}

Advances in the technology of oceanic remote sensing from space can be envisioned in two categories. One category is the kinds of ocean data that can be measured or characterized by remote sensing. The other is the scope of ocean monitoring in terms of coverage and completeness, duration, and dissemination of information products. Advances in either of these categories would greatly increase the usefulness of remotely sensed data to the ocean community.

With regard to kinds of data, the present and foreseeable capability consists of direct measurement of physical quantities (e.g., surface water temperature, visual color, roughness patterns, wave height, and topography) at or near the air-sea interface. From these measurements, surface wind speed and direction, currents, and chlorophyl1 concentrations can be inferred. The utility of oceanic remote sensing would be extended by the capability to make measurements of interest to marine biology, chemistry, and geology. The direct measurement of carbon dioxide concentration is an example of this extension. Similarly, one can envision benefits to ocean resource management should it become possible to measure primary chemical nutrients and larger marine organisms. Detection of concentrations of fish, combined with dissemination of the information to fishermen on a useful time scale, would have an enormous impact on an industry that spends the major portion of ship time hunting rather than harvesting. New active techniques (blue-green lasers, for example) may be capable of extending the depth 
of remote sensing to tens of meters. Increases in sensing depth will benefit marine geology. The utility of remote sensing to coastal zone and estuarine studies could expand dramatically with even modest increases in sensing depth.

The second category of important advance in capability identified by the Panel is that of the scope or scale of ocean monitoring. The elements that would be required for a comprehensive ocean monitoring system have been developed and tested. The important difference would be in scope of the total system rather than in the kind of measurements. Orbiting platforms could bring major improvements in system resolution and sensitivity. Use of larger apertures, of the order of tens of meters, would bring improvements in resolution. A large man-tended station would be consistent with the broad payload complement, the large apertures for the microwave instruments, and the requirement for long-term data continuity.

\section{Data Distrubtion and Utilization}

Because of the short temporal scales of some ocean phenomena, a major consideration is the timely availability of data end-products. Following is a discussion of some of the factors that are applicable either to an ocean satellite system or to a space station or platform carrying a complement of ocean sensors.

Raw data must be available in near real-time to those responsible for sensor health, to value-added industries that convert data to information products, and to researchers involved in real-time experiments. This requires high-speed communication between remote sensing satellites, a space station, or a space platform and research and commercial users. Processed data should be made readily available to commercial and government centers charged with satisfying end-user needs for geophysical units and for analysis and forecast products. Ship-routing services, fishery location aids, and drilling platform advisories are activities in which information is needed at least twice daily. On the other hand, computer and other ocean-process modeling activities require a continuous flow of data for several years. Finally, it is necessary to establish, in concert with users, what subsets of raw and reduced data will be permanently stored. 


\section{CONCLUS IONS}

There is a growing need for ocean data. The requirements applying to ocean satellites would apply equally to space stations or space platforms carrying ocean-observing instruments.

The acquisition of ocean data from space should be improved, collection of the data should be increased, and the data should be made available to ocean users in a timely manner and in formats that are useful to them.

Since the oceans cover regions that extend nearly to the earth's poles, remote sensors must be carried on spacecraft in high-inclination orbits.

Data from remote sensing instruments must be continuously validated by measurements made at the earth's surface from ships, buoys, and aircraft. The data from ships, aircraft, and buoys should be integrated with remotely sensed data from space in a single ocean-data system.

With regard to the utility of man in space with respect to acquiring ocean data, the Panel makes the following observations. Human participation may be useful in the development of new instruments and for short-duration specialized experiments, but man would not play a meaningful role in the acquisition of data on a continuing basis.

The Panel sees a need for the ability to assemble, repair, or modify remote sensing spacecraft in orbit. Seasat is a good example-it is understood that this costly spacecraft could have been restored to useful operation if the ability to retrieve it had existed. Another example is the construction of very large antennas. The Panel recommends that spacecraft be designed so that they can be repaired or modified in orbit.

\section{REFERENCES}

Committee on Earth Sciences. 1982. A Strategy for Earth Science from Space in the 1980's. Part 1: Solid Earth and Oceans. Washington, D.C.: National Academy Press. 
International Council of Scientific Unions. 1980.

Oceanography from Space. Committee on Space Research and Scientific Committee on Oceanic Research;

Inter-union Commission on Radiometeorology. Venice, Ita1y.

Joint Scientific Committee/Committee on Climate Change and the Ocean. 1981. Report of the Meeting on

Coordination of Plans for Future Satellite Observing

Systems and Ocean Experiments. Chilton, United Kingdom.

National Advisory Committee on Oceans and Atmosphere.

1981. Ocean Services for the Nation: National Ocean

Goals and $O b j e c t i v e s$ for the $1980^{\prime} \mathrm{s}$. Washington,

D.C.: U.S. Government Printing Office.

National Aeronautics and Space Administration. 1981.

Satellite Altimetric Measurements of the Ocean. TOPEX

Science Working Group. Pasadena, Calif.: Jet

Propulsion Laboratory.

National Aeronautics and Space Administration. 1982a.

Scientific Opportunities Using Satellite Surface Wind

Stress Measurements over the Ocean. Satellite Surface

Stress Working Group. Washington, D.C.

National Aeronautics and Space Administration. 1982b.

Science Requirements for Free-Flying Imaging Radar

(FIREX) Experiment. Pasadena, Calif.: Jet Propulsion

Laboratory.

National Aeronautics and Space Administration. 1982c.

Seasat Data Utilization Project Report. Pasadena,

Calif.: Jet Propulsion Laboratory.

National Center for Atmospheric Research. 1981. Needs, Opportunities, and Strategies for a Long-Term Oceanic Sciences Satellite Program. NASA/NOSS Science Working Group. Boulder, Colo.

Ocean Sciences Board. 1982. Two Special Issues in Satellite Oceanography: Ocean Dynamics and Biological Oceanography. Washington, D.C.: National Academy Press.

Stewart, R. H. 1982. Oceanography from Space. 33rd Congress of the International Astronautical

Federation. Paris. 


\section{SATELLITE COMMUNICATIONS}

The outlook for satellite communications is different than that for other space activities in that this represents the one space applications area where there is a healthy and rapidly growing industry. The momentum that already exists in this industry indicates that considerable progress may be expected during the balance of this decade.

In response to the question of what practical applications of space systems may be expected in the $1990 \mathrm{~s}$, the Panel focused the majority of its attention on potential new services that have promise for this period. This chapter is an examination of the field of satellite communications, portraying the current state of affairs, projecting what change might occur in the future, and defining what impact future needs might have on the development of future space programs.

The Panel noted that the 1979 report of the Committee on Satellite Communications of the Space Applications Board explored many of the issues related to practical applications and technology development in the area of satellite communications (Committee on Satellite Communications, 1977). This report treats many of the same issues and focuses attention on the space station.

\section{MAJOR DOMESTIC SATELLITE COMMUNICATIONS SERVICES}

Today communications satellites are in wide use for commercial and military purposes. The growth of the domestic satellite (domsat) communications industry has followed the pattern of many successful new telecommunications services during their early years. It is now characterized by a fast-growing demand for services that may outstrip the capacity of available facilities in 
the foreseeable future. While a growing number of satellite suppliers and carriers are providing the satellite capacity to meet present and future demands, advances in technology and the prospect of new and innovative services continue to stimulate the growth of the market. The market for services and the public benefits provided are expected to grow dramatically over the next several decades.

Currently, more than a dozen domestic satellites provide over two hundred transponders located in geostationary orbits over the United States. These communications satellites are spaced approximately $4^{\circ}$ apart in the geostationary orbital arc in order to avoid mutual radio-frequency interference. The Federal

Communications Commission's (FCC) authorization of domsat expansion of 4 December 1980 would permit the inclusion of five additional satellites. Other authorizations are expected, along with a change to $2^{\circ}$ spacing at $\mathrm{C}-\mathrm{band}$, as we11 as at $\mathrm{K}_{\mathrm{u}}$-band $(14 / 12 \mathrm{GHz})$.

U.S. domsats have been allocated $500 \mathrm{MHz}$ of bandwidth at both the $\mathrm{C}$ - and $\mathrm{K}_{\mathrm{u}}$-bands. Satellites using separated frequency bands can be collocated at the same longitude because the probability of physical collision is negligible. An additional $300 \mathrm{MHz}$ has been allocated by the International Telecommunications Union at $\mathrm{C}$-band, but is not currently planned for use in U.S. domsats because of the military use of this band.

In the $\mathrm{K}_{\mathrm{a}}$-band $(30 / 20 \mathrm{GHz})$, a bandwidth of $2500 \mathrm{MHz}$ has been allocated for satellite service. This band currently is subject to outages in rainstorms, but further advances in technology may relieve most of this limitation.

Spot beams formed by large spacecraft antennas can illuminate small areas called "footprints" on earth. If these footprints are sufficiently isolated from one another, any given frequency band can be reused in separate footprints. This results in multiple reuse of the allocated spectrum. Frequency reuse at $\mathrm{c}$-band is limited, however, because of adjacent beam side lobe interference and geographically skewed traffic distribution in the most developed portions of the country. Triple-frequency reuse at $\mathrm{K}_{\mathrm{u}}$-band seems achievable with current technology.

Currently, the allocated bands are divided into $40-\mathrm{MHz}$ segments. Allowing for guard bands, each segment supports a single transponder with a radiofrequency bandwidth of approximate1y $36 \mathrm{MHz}$. Eventually, improvements in modulation techniques could double the traffic-carrying capacity. 
Advantages would accrue from interconnecting domsats. If intersatellite links were developed so that signals could be switched between domsats, then a larger number of earth stations could be interconnected. These

intersatellite links could be radiofrequency links between separate domsats, or in the case of platforms carrying multiple communications payloads the interconnecting links could be hard-wired. In either case, the interconnections could enhance the network available to each earth station.

This section concentrates on three major domsat services that are now being provided by carriers or that appear to have high potential in the commercial marketplace and the public sector. They are fixed satellite service (FSS), direct broadcast service (DBS), and mobile satellite (MSAT) service.

\section{Fixed Satellite Service}

Included in the fixed-service category are point-to-point voice, video, and data services delivered either through commercial trunking networks or private networks, as we 11 as distribution (point-to-multipoint) services, of which the most familiar is the distribution of television programming.

In two parallel studies sponsored by the National Aeronautics and Space Administration (NASA) in 1979, forecasts of the fixed-service market through the year 2000 were offered by Western Union and U.S. Telephone and Telegraph Corporation (Kratochvil et a1., 1983). These forecasts were updated recently by a NASA internal analys is (Gamble et al., 1979). The forecast is in terms of equivalent $36-\mathrm{MHz}$ transponders; a $36-\mathrm{MHz}$ transponder is a convenient measure of capacity, since it will support 2,400 one-way voice circuits or two one-way color television circuits.

The demand forecast in the original 1979 NASA analys is for the year 1982 was 140 transponders (there are now more than 250 in orbit); for 1985, 350; for 1990, 650; and for the year $2000,2,580$ transponders.

The kinds of service predicted for 1990 are 10 percent data, 40 percent video, and 50 percent voice; for the year 2000 , service use is predicted to be 15 percent data, 25 percent video, and 60 percent voice. These percentages contrast with current demand, which is dominated by the 60 to 70 percent use for video services. 
The number of FSS satellites that can be accommodated in orbit and the number of equivalent $36-\mathrm{MHz}$ transponders that can be carried by each satellite depends on how much information can be handled by each transponder, and this varies with the modulation and signal-compression techniques in use. Nominal advances in such techniques have been accounted for in the FSS forecasts previously discussed, and hence capacity in terms of transponders is the proper measure for comparisons with the forecast.

Currently, $500 \mathrm{MHz}$ at C-band can be used twice on each satellite through the use of orthogonal polarization of the signal. This provides 24 equivalent transponders on each C-band satellite.

Similar polarization reuse can be achieved on $\mathrm{K}_{\mathrm{u}}$-band satellites, and an additional frequency reuse can be achieved using a spot beam antenna. Current methods should enable the formation of $1^{\circ}$ to $1.5^{\circ}$ spot beams (probably aimed toward the east and west coasts of the continental United States), which, when combined with polarization isolation, would increase the frequency reuse to three times. Assuming 12 actual transponders per satellite, this would provide the equivalent of 36 transponders.

The use of 24-equivalent transponder c-band satellites and of 36-equivalent transponder $\mathrm{K}_{\mathrm{u}}$-band satellites both spaced at $2.5^{\circ}$ would result in total U.S. domsat capacity of 1,512 equivalent $36-\mathrm{MHz}$ transponders (648 of c-band and 864 of $\mathrm{K}_{\mathrm{u}}$-band), which is more than 1000 transponders short of the year 2000 demand forecast earlier (indicated to be 2,580 transponders). At $\mathrm{K}_{\mathrm{u}}$-band, wide-area distribution services could be addressed in 1995 by $0.75^{\circ}$ spot beams covering the continental United States and providing four-time frequency reuse in a time division multiple access (TDMA) mode.

The use of $\mathrm{K}_{a}$-band (for which technology is being developed but is not yet available) would provide for eight new satellites. As the radiofrequency wavelength decreases (higher frequency), the effect of atmospheric attenuation on the signals is more pronounced at ground station antennas with low elevation angles, resulting in a decrease in the number of usable satellites. The $2500 \mathrm{MHz}$ of $\mathrm{K}_{\mathrm{a}}$-band allocation would allow for 60 transponders per satellite without frequency reuse, but it is unlikely that $\mathrm{K}_{\mathrm{a}}$-band satellites would be implemented without spot beam reuse. Link power requirements at $\mathrm{K}_{\mathrm{a}}$-band would dictate the use of a high-gain spot beam antenna, and thus frequency reuse would be inherent. A frequency 
reuse of three would permit a U.S. domsat capacity of 1,440 transponders at $\mathrm{K}_{\mathrm{a}}$-band. This capacity, when combined with the $\mathrm{C}$-band and $\mathrm{K}_{\mathrm{u}}$-band capacities calculated above, will meet the forecasted demands for the year 2000.

At $\mathrm{K}_{\mathrm{a}}$-band, it should be possible by 1990 to produce 20 to 40 fixed beams of $0.3^{\circ}$ beam width and 35 -decibel side lobe isolation for trunking applications. During the $1980 \mathrm{~s}$, the $\mathrm{K}_{\mathrm{a}}$-band beam-forming circuitry for a multiple-beam antenna will be fabricated largely from discrete components. By the year 2000, the discrete components should give way to monolithic technology, providing weight and size reductions and reliability improvements.

\section{Direct Broadcast Sate1lite Service}

A new direct-broadcast satellite (DBS) service is expected to be offered by several suppliers by 1 ate 1984. Initially it will deliver television programming direct from the satellite to the viewer's premises through small receiving antennas. Because DBS is a new service, forecasts of its market demand are more uncertain than are those for fixed services. However, a comprehensive forecast was presented by the Federal Communications Commission's Regional Administrative Radio Conference Advisory Committee (RARC, 1983) in its final report. The committee's forecast, made in terms of standard TV channels, was for 36 to 46 channels in the year 1986, and 68 to 215 channels in the year 2000. Since the United States achieved the goals sought by the 1983 RARC, it appears that the lower market demand in the year 2000 can be accommodated with current or near-term methods.

The emphasis in DBS between 1990 and 2000 wil1 be on developing $100-$ to $200-W$ power amplifiers that are reliable and efficient, and on mass production of low-cost home terminals.

\section{Mobile Satellite Service}

Mobile satellite (MSAT) service, another new service under study, involves the direct delivery of voice and low-data-rate communications via satellite between mobile radio units and the U.S. switched telephone network. The system providing this service would augment the planned 
cellular mobile radio telephone systems* in urban areas by providing satellite coverage in rural and low-density population areas. Such a system could also provide commercial mobile radio (dispatch) services in rural areas. If a satellite system was implemented in conjunction with existing or planned terrestrial mobile radio systems, it would provide for nationwide mobile radio service.

Through the next two decades, the terrestrial cellular system is targeted to large urban Standard Metropolitan Statistical Areas (SMSAs), and it is unlikely that it will ever be implemented in small towns or in rural areas. This means that in the year 2000 there will be an unserved population of about 77 million people, and about 50 million of these people will have little hope of ever obtaining service from the cellular system.

Thus, if one applies typical market-potential factors (about one percent is normal) to the unserved cellular system market, a probable market for MSAT should be between 500,000 and 700,000 mobile radio telephone users. To capture this market, it is felt that the MSAT service must not only be comparable in cost to cellular service, but that the MSAT service and system characteristics must be compatible with cellular service and system characteristics.

In addition, there are approximately 1 million current commercial mobile radio units in use in the non-SMSA counties of the United States, and it is estimated that 20 percent, or 200,000 , of these users are receiving unsatisfactory service from the present system because of range and/or coverage problems. The Panel believes that satisfactory service could be provided by a MSAT system if it can be cost competitive to that of current services.

While there are other potential users of a MSAT service--for example, the oil and gas industry or emergency medical services--the sum of mobile radio telephone and private mobile radio users discussed above represents at least 700,000 users who need better service.

To achieve MSAT system capacities approaching the potential user needs, frequency reuse must be employed. This is possible with spot beams, but because of the low

\footnotetext{
*In cellular systems, the geographical areas are divided into cells, each served by a terrestrial multichannel repeater station. Frequency is reused in nonadjacent ce11s.
} 
frequencies involved to provide compatibility with terrestrial service, large satellite antennas are required. An antenna on the order of $50 \mathrm{ft}$ in diameter would allow for a frequency reuse of two and a capacity of 40,000 to 240,000 users. But uncertainties in FCC frequency and orbital location allocations, similar to those affecting DBS, make mobile satellite capacity uncertain.

\section{DEVELOPMENTS EXPECTED THROUGH THE $1980 \mathrm{~s}$}

Growth of satellite telephony services is expected to occur in domestic, regional, and international areas, as advanced countries continue to augment existing terrestrial systems. Continued use of the $6 / 4 \mathrm{GHz}$ band will be supplemented by growth in the use of the $14 / 11 \mathrm{GHz}$ band. It is also reasonable to expect some operational use of the $980 / 450 \mathrm{MHz}$ band for mobile applications, augmenting the cellular system, as well as experimental and some operational use of the $30 / 20 \mathrm{GHz}$ band. Developments that would assist growth of direct broadcast services are high-power broadcast satellites (in the range of one-half to one million effective radiated watts), and high-efficiency shaped-beam satellite antennas that confine the broadcast signal to the desired region and permit low-cost receiving earth stations.

Digital television transmission will become attractive in the foreseeable future. Use of digital techniques will require developments in source coding and error control, low-cost devices to convert the signal from analog to digital form, and inexpensive video receivers that operate directly from a digital signal. Standard format converters will be required for international transmission.

Wideband services include transmission of digital data, computer networking, and point-to-point video transmission. Wideband services can be expected to make extensive use of both the $6 / 4-$ and $14 / 11-\mathrm{GHz}$ bands in the 1980s. The 30/20-GHz band may be used for certain high-data-rate applications such as electronic mail and digital trunking, and some operational $30 / 20-\mathrm{GHz}$ systems wi11 emerge by 1990 .

Communications services that use small transportable terminals with small antennas are now available to some users. Existing systems provide limited 1 and, sea, and air services, but are expected to grow throughout the 
1980s. The Panel estimates that by 1990 more than 6,000 maritime installations will be in use worldwide, requiring almost 100 voice channels in the Atlantic and 50 each in the Indian and Pacific oceans. If satellites were equipped with large antennas and high power, a much larger market for systems using smaller antennas would exist.

\section{POTENTIAL NEW SERVICES--1990-2000}

The Panel identified potential new services that could become available in the decade 1990-2000: personal and business paging service; broadcast FM service to mobile users (clear-channel broadcast-type service); air and ship traffic control and safety services; vehicle emergency alerting and location; disaster warning to individual homes; and multimode land and maritime remote-area service.

\section{Persona1 and Business Paging Service}

Today mobile radio is used mainly for telephone extension service and dispatching (police, fire) in which a one-way broadcast signal is transmitted from a central location in response to an incoming request. The transmission is ordered to trigger visual or auditory response in a small portable receiver, often called a "beeper." Since the system is one-way, the called party uses another communications medium for response. The growing popularity of this service is now confined to urban areas in which a concentration of users coincides with the available radio range of a few miles.

A satellite-based paging service could permit area coverage to the vast majority of the nation's nonurban areas and augment the market for urban areas as well. Because of easy and inexpensive compatibility with existing receivers, such a paging service should operate in a frequency band designated for mobile use, if band allocations permit. Service augmentations, such as display of the phone number to call back or short messages, could be included。 Only modest satellite power is required, because a short simple message and address requires only a narrow bandwidth. 
Clear-Channe1 FM Broadcast Service to Users

Today commercial FM broadcasts are limited to line-of-sight coverage, and serve urban, suburban, and some portion of rural areas. The effects of terrain and building blockage, multipath fading, and distortion inhibit mobile use. An FM broadcast satellite for rural and mobile use could be attractive; it could also have utility as a universal warning and alerting system employing inexpensive receivers. Some changes in band allocation or licensing rules would be necessary in order to provide a few clear channels, but the improvement in quality of service would be in the public interest:

\section{Air and Ship Traffic Control and Safety Services}

Few existing or planned air traffic control and vessel traffic service systems are adequate. A combination of satellite observation, position location, and communication services could help justify an improved future system. This complex group of multifrequency communication and navigation systems would be improved and its cost lowered by use of a satellite-based central observation and control facility.

\section{Vehicle Emergency Alerting and Location System}

The growing use of simple beacons that are triggered by impact or by seawater to provide an alerting and homing signal for rescuers is being improved by an international satellite-based project called COSPAS-SARSAT. However, the beacons are to be used only for certain aircraft and ships. The extension of use of these beacons to ground vehicles and individuals for alerting and location purposes should broaden the envisioned benefits of quick rescue. An expanded system for vehicles and individuals could use an integrated set of satellites at geosynchronous orbit (for continuous detection) or at low earth orbit (for simplified Doppler positioning), with rescuer communications included if necessary. 


\section{Disaster Warning to Individual Homes}

The broad coverage of satellite broadcasts could be used for alerting individual homes and businesses that currently have inadequate reception to pending natural disasters. Current warning systems, integrated with weather broadcast services, are intended to cover al1 areas of the United States, but terrain blockage, multipath distortion and fading, and building attenuation cause the effectiveness to be marginal in many locations.

The use of a satellite system to augment or replace the existing terrestrial VHF-FM broadcast system could improve service, reduce operating costs, and overcome user apathy. Additional utility might be achieved by providing information (in addition to the alert) that would help people prepare for natural disasters, and by providing postdisaster communications for assessment and rescue control.

Multimode Land and Maritime Remote-Area Service

Radio is the practical medium in the vast thinly populated areas of the earth's surface for communications related to safety, survival, business, and education. A satellite system could provide the most effective coverage for rural and remote areas, but the technology for such a service at affordable costs has yet to emerge.

\section{CONCLUSIONS AND RECOMMENDATIONS}

The Panel, in examining the technical and operational requirements for the conceptual design of a space platform or a space station, makes the following conclusions:

Almost a11 communication services projected for the period 1990-2000 could be provided at geostationary earth orbit, and all satellites and their deployment could be accommodated by Space Shuttle launch capabilities. This assessment also applies to presently contemplated direct-broadcast satellite national television services (DBS-TV), a1though an advanced DBS-TV satellite might have characteristics resembling a platform. 
Nearly all telecommunication modes that could be performed at low earth orbit are better accomplished at geosynchronous orbit. A possible exception is a hypothetical medium-frequency broadcast service.

A space station or platform could be useful in two major ways: (1) as a fuel depot, to reduce launch costs, or to allow greater payloads, and (2) as a means for allowing assembly of, modification to, or refurbishment of in-orbit satellites. Also, some advantages would accrue from interconnecting domestic satelites carried on a space platform.

An unmanned geosynchronous-orbit operational platform could serve as the support platform for varied communications missions. The desired characteristics of orbit, power, attitude contro1, and thermal control for such a platform are:

Orbit $-0^{\circ}$ angle inclination with 24 -hour synchronous orbit

Power--25-kW power level initially with an eventual $100-\mathrm{kW}$ power leve1

Attitude contro1-- $1^{\circ}$ to $3^{\circ}$ inclination about three axes with finer control by individual payload subsystems

Thermal control--centralized thermal control-heat rejection system sized to approximately 75 percent of the power available

If a low-earth-orbit service station is planned, the Pane 1 recommends the following characteristics in relation to orbit, power, attitude control, and fuel storage:

Orbit--altitude consistent with long life and inclination in the $28^{\circ}$ to $0^{\circ}$ range consistent with requirements for raising and lowering orbits of spacecraft

Power--sufficient to operate station/platform housekeeping services, estimated to be in the 15- to 25-kW range

Attitude control--flexible requirements (few degrees acceptable) for long periods; for short periods, vernier control necessary to permit acquisition and fueling of spacecraft

Fue1 storage--adequate for boost to geosynchronous orbit (approximately 15,000 1bs) 
The role of man in space with respect to satellite communications appears to be limited. The functions of fueling and assembly of spacecraft, which require human presence, have been noted.

\section{REFERENCES}

Committee on Sate1lite Communications. 1977. Federal Research and Development for Satellite Communications. Washington, D.C.: National Academy of Sciences.

Gamble, R. B., et a1. 1979. 30/20 GHz Fixed Communications Systems Service Demand Assessment. ITT-U.S. Telephone and Telegraph Corporation, Final Project Review at NASA Lewis Research Center, Cleveland, Ohio.

Kratochvil, D., et al. 1983. Satellite Provided Fixed Communication Services: A Forcast of Potential Domestic Demand Through the Year 2000. Western Union, Final Project Review at NASA Lewis Research Center, Cleveland, Ohio.

Regional Administrative Radio Conference Advisory

Committee. 1983. Final Report. Washington, D.C.: Federal Communications Commission. 


\section{MATERIALS SCIENCE AND ENGINEERING*}

\section{INTRODUCTION}

This chapter explores the relationship of the materials science and engineering (MSE) community to the possible availability at some future time of an unmanned space platform or manned space station. How might it benefit the materials science and engineering community to have access to the space environment, specifically via a space platform or manned space station, for research and for eventual applications? What scientific and technological opportunities might be provided by a space station as compared with those available to materials science and engineering on the space Shuttle and in ground-based research? The Panel addresses these and related questions.

In order to assess the potential use of a space station, the Panel felt it necessary to review the past and present status of the National Aeronautics and Space Administration's (NASA) materials processing in space (MPS) program . The Panel reviewed materials experimentation in a microgravity environment (both ground- and space-based) and assessed the needs of various MSE activities for longer experiment time. In addition, the Panel considered whether the various MSE activities could utilize a space station or platform advantageously.

The Panel expresses its appreciation to the following people who participated in discussions: John $R$. Carruthers, Hewlett-Packard Laboratories; John A. Graham, Deere and Company; David Keaton, GTI Corporation; Fortunato J. Micale, Sinclair Laboratory; and David W. Richman, McDonne11 Douglas Astronautics Company. 
Finally, the Panel described the requirements for a space station that would be needed to serve the MSE community, including gravity level, power requirements, and flight hardware design.

\section{BRIEF HISTORY OF NASA'S MATERIALS PROCESS ING IN SPACE PROGRAM}

Since scientists began to consider the space environment and especially since the early days of space flight, it has been recognized that materials, particularly in a fluid state, behave differently in space than they do on earth. As it became recognized that the behavior of materials in space might lead to useful developments, opportunities for low-gravity (low-g) experiments became available in rockets and spacecraft, both unmanned and manned. For example, exploratory experiments in crystal growth, bioprocessing, and containerless processing were conducted during the 1973-74 Skylab missions. Most of these early experiments were driven by the exigencies of flight opportunities and were poorly conceived, in the sense that while most went through their prescribed duty cycles, the hoped-for results were often masked by extraneous phenomena.

Nevertheless, some premature claims were made for new and possibly useful materials or materials-related processes in space. Most of these claims were not validated, usually because of the complexity of the experimental situation, the lack of sufficient ground-based science for comparison, and the lack of opportunity for additional trials in space. NASA, in an attempt to find new and broadly based purposes following the culmination of the Apollo program in the mid-1970s, heralded the potential of MPS as an activity that would eventually create new business ventures and profits for the private sector. There were hopes of exotic alloys, nearly perfect crystals, and new drugs that would cure disease, each so rare and unique that the high cost of space flight and extraterrestrial processing would be warranted.

Subsequently, NASA's MPS program was studied in detail by the National Research Council's (NRC) Committee on Scientific and Technological Aspects of Materials Processing in Space (STAMPS). Among the conclusions and 
recommendations in the STAMPS report, published in 1978, were the following:

NASA's MPS program had been weak; nevertheless, some work done in space has shown that valid experiments can be planned, manipulations performed, and useful samples returned to earth for study. The Committee found that "the work that gave productive results had a sound base in terrestrial research."

". - space experimentation will have little value unless its planning is founded on substantial earth-based information and unless the results are coupled to those of complimentary terrestrial programs."

The principal values of the space environment are the availability of low-gravitational acceleration for long periods of time and the effect of the space environment on phenomena related to buoyancy--e.g., containerless processing, solidification, and transport processes under conditions of reduced convection.

The committee had "not discovered any examples of economically justifiable processes for producing materials in space."

The program should emphasize the use of the space environment for the scientific study of materials phenomena in an effort to gain new knowledge and possibly improve materials processing on earth.

Following the report of the STAMPS committee, there was significant improvement in the MPS program. Some highlights of the succeeding (post-1978) era are listed below.

An extensive, ground-based program of research was developed to provide the knowledge needed to set potential materials research in space in a proper scientific context.

A peer review system was instituted to select only those proposals that had true scientific and technological merit and to decouple their selection from funding stimuli or from the need merely to fill flight opportunities.

A higher quality of principal investigator and of ideas was attracted to the program; conclusive scientific findings surfaced and were published in the 1iterature.

A program in joint ventures was established by which NASA and the private sector could cooperate on a 
no-funds-exchanged basis to test systems for space processing that might someday be commercially viable.

A committee of materials scientists and engineers, STAAC, was constituted to monitor the program and to help ensure that the lessons learned from the preceding era would be heeded.

\section{PRESENT STATUS OF NASA' $S$ \\ MATERIALS PROCESSING IN SPACE PROGRAM}

At present, NASA's MPS program includes ground-based experiments, reduced-gravity experiments, and commercial ventures. A discussion of each area follows. Also, in view of the importance attached to the joint venture activity on electrophoretic separation of biological materials, the Electrophoresis Operations in Space (EOS) project is discussed in a separate section.

\section{Ground-Based Experiments}

NASA's current MPS program involves approximately 70 principal investigators associated with 50 organizations--31 universities, 12 industrial organizations, and 7 national (government-supported) laboratories. Funding in FY 1983 to support the science base and approved flight-support experiments totaled $\$ 12.5$ million and was distributed in the form of single-investigator contracts and institutional block funds. Approximately two-thirds of these funds supported a broad, applied-research program contributing to the improvement of the science base.

The areas currently funded by the MPS program include:

Containerless technology, which involves development of techniques and construction of hardware for using acoustic, electrostatic, and electromagnetic fields to position material under microgravity conditions

Containerless science, which includes experimental and theoretical studies of the behavior of materials, especially in the molten state, when removed from physical contact with confining walls. Such studies include nucleation, glass formation in undercooled systems, thermophysical measurements on levitated samples, and buoyancy and convection in levitated systems. 
Crystal growth, which involves modeling of crystal growth processes, thermodynamic and kinetic studies of crystal formation from vapors and liquids, and growth of crystals under terrestrial and microgravity conditions

Solidification and fluid processes, which includes the response of microstructure to thermal gradients, freezing rate, and gravity vector orientation and studies aimed at understanding how convection and sedimentation affect cast and composite materials

Bioprocessing, which involves separation of biologically interesting materials (cells, viruses, proteins, etc.) using techniques that can benefit from the reduction in gravity level

cloud physics, which deals with ice growth in supercooled water vapor and includes modeling of microscale transport phenomena.

Extraterrestrial materials processing, which involves identification, acquisition, and processing of lunar, asteroidal, and meteoritic materials, including studies of the chemical extraction of useful materials from simulated extraterrestrial matter

Combustion science, which studies kinetics of flame propagation and reactions in combustion systems under terrestrial and orbital conditions

The program is monitored by a system of six science working groups (SWGs) formed under the auspices of the Universities Space Research Association (USRA). Active SWGs now include those for Containerless Processing, Solidification, Float Zoning, Bioprocessing, Fluids, and Transport and Combustion. The SWGs report to NASA through USRA and provide periodic peer reviews.

In the five-year period since the STAMPS report was pub1ished, the ground-based research program has improved in breadth and quality. The portion of MPS program funds allocated for nonflight science support has increased from less than 20 percent in 1976 to more than 40 percent of the total program budget. The scientific publication rate has risen from 10 papers in 1976 to 35 papers in 1980 , with a projection of more than 70 papers published in 1982.

The possibility of selecting flight experiments from the ground-based research program now exists, but limited flight opportunities and hardware development remain pacing factors. 
Reduced-Gravity Experiments

The Panel notes with approval that NASA's MPS Program office has increased access to reduced-gravity-level environments. NASA provides a variety of opportunities, including drop tubes and towers, aircraft, and sounding rockets, all of which produce relatively short-duration microgravity environments--several seconds in drop tubes and towers, a half-minute in $\mathrm{KC}-135$ and $\mathrm{F}-104$ aircraft, and five minutes in sounding rockets.

In addition, the Space Processing Applications Rocket (SPAR) program has conducted some nine flights over a period of approximately five years with about 30 experiments carried out. The SPAR experiments were flown in a timely manner at relatively low cost, with few failures and with some useful scientific results.

In regard to the Space Shuttle, opportunities for flying experiments have just begun, but it appears certain that these will continue to remain at a premium, even for worthy projects, and that the frequency of these opportunities will limit the program.

\section{Commercia1 Ventures}

Commercial involvement with NASA's MPS program takes two forms at present: (1) the Joint Endeavor Agreement (JEA) and (2) the Technical Exchange Agreement (TEA). The purpose of the JEA is to provide easier access to space flight opportunities for organizations that have an interest in developing commercially viable products and processes and that are willing to assume an appropriate financial risk. At present, JEAs have been negotiated with several leading national firms. TEAs are designed to permit use of the characteristics of low earth orbit and short-duration opportunities to study effects on materials in order to improve the product or process in its ordinary terrestrial setting. TEAs have been established with some six national firms.

There has been very limited experience to date with commercial ventures. However, these experiences suggest that commercial materials processing activities in space might fall into three general areas: (1) utilization of space as an applied-research tool, (2) on-orbit services provided at a cost to the customer, and (3) scenarios leading to commercial production of products manufactured in space. 
Finally, inasmuch as the flight opportunities aboard the Space Shuttle have just begun, it is premature to judge how important or advantageous a space station might be to the MPS program. However, the major concerns of the MSE community center on ease of access, turnaround time, hardware development and integration, and cost--precisely the same concerns the community faces regarding use of the Spacelab/Shuttle for the current MPS flight program.

\section{Electrophoresis Operations in the Space Program}

In July 1982, on the fourth flight of the Space Shuttle, McDonnell Douglas Corporation and Ortho Pharmaceutical Corporation (a division of Johnson \& Johnson) carried out one phase of their Electrophoresis Operations in Space (EOS) program under a JEA with NASA. The objective of the electrophoresis experiment performed at that time was to verify that concentrated biological materials flow at greater volume and separate with good resolution under microgravity conditions. McDonnell Douglas reported that all test objectives were met (Yardley and Rose, 1983 personal communication). Separations of rat and ovalbumin, very difficult to perform in earth's gravity, and separations of a tissue culture of commercial interest were accomplished. With regard to the quantities producible on earth and in space, the company reported its research had shown that 0.2 percent is the maximum concentration of albumins that can be separated on the ground, whereas in the 1982 Shuttle experiment a 25 percent concentration was possible. Thus the 125 times greater concentration of biological materials and the 4 times greater volume resulted in throughput improvement of about 500 times (McDonne11 Douglas, "Results of McDonne11 Douglass Electrophoresis Experiment on STS-4," November 8, 1982). Comparable success was achieved in the separation of the tissue culture media.

Under this EOS program, two Shuttle flights are scheduled for 1984 with the purpose of producing significant quantities of processed material for use by Ortho in clinical testing (Yardley and Rose, 1983, personal communication, p. 2); plans call for testing a production prototype unit in 1985, and for clinical programs leading to Food and Drug Administration (FDA) approval in 1987. The production prototype unit, designed to become the first commercial production unit following FDA approval of the processed material, would be capable 
of operating in the Shuttle orbiter bay, or as a free-flier supported in orbit by the Shuttle or a prospective space station.

However, in the Panel's view, even though increased throughput was demonstrated in space, it appears that free-flow electrophoresis may become a technology with limited practical industrial application, and that some simpler, less costly alternatives are available on earth. For instance, in the last decade, rapid advances in the technology of separation (greater selectivity and throughput) and advances in biology have resulted in the commercial availability of biologically active compounds.

\section{THE ROLE OF MAN IN SPACE}

This section discusses the characteristics of present and possible future (e.g., manned space station) microgravity environments, in an effort to understand better the limitations and advantages of each, and to explore the advantages of real-time interactions by a human that might be provided in a manned space station.

A variety of facilities are now available for conducting experiments in a microgravity environment. Following is a list of examples:

Drop towers provide a microgravity environment for up to 6 seconds.

Aircraft such as $\mathrm{KC}-135 \mathrm{~s}$ and $\mathrm{F}-104 \mathrm{~s}$ flying in ballistic trajectories provide a microgravity environment for up to 50 seconds.

Rockets provide a microgravity environment for up to 5 minutes.

Earlier one-shot orbiting facilities--e.g., Skylab and Apollo-Soyuz--provided several hours of microgravity environment.

The Space Shuttle and Spacelab will, for the next several years, provide a number of opportunities for conducting experiments in a microgravity environment for periods of up to 7 days.

Materials scientists and engineers have used and will continue to use these facilities to conduct experiments under conditions of microgravity, albeit in some cases for a very short time. However, there are disadvantages to using these facilities, including a significant loss in versatility in the equipment that can be used, a decrease in the availability of support functions, the long time 
required between conceiving and carrying out an experiment, and the meager real-time human attention and intervention that are available. Spacelab is expected to be manned; however, only limited interactive capabilities with materials science experiments will be possible. Highly automated equipment is being designed for Spacelab, instead of equipment that would take advantage of man's presence and unique capabilities. Hence, even if particularly careful planning and preparation are given to activities carried out in these facilities, the programs become one-shot experiments that have a high chance of failure.

To meet the needs and exploit the full potential of materials research, a space station would have to provide a laboratory that significantly alleviated the restrictions of experimentation in currently available space facilities. A space station could diminish the constraints on the equipment used, could provide more electrical power and cooling capability, and make possible much longer continuous periods of experiment time in microgravity. If a space station were available for materials research, the time between conception and conduction of the experiment could be reduced significantly. And, most important, real-time human observation and intervention in an adaptive mode would be possible, which is particularly important in the event of unexpected results. However, this latter capability would require the presence of personnel with experience and ski11 in conducting materials experiments.

The Panel believes, therefore, that the basic style or mode of the materials science and engineering experimentation that could be conducted in a manned space station is very different from most of that conducted heretofore in space. In particular, the presence of man in a space station--presumably a trained professional or one trained to interact by communication in real-time with a technician or scientist--would allow for an interactive mode of materials research in space that is much closer to that now conducted in laboratories on earth. Space laboratories in a manned space station could be equipped not only to observe and collect data, but to alter and adapt experiments, based on observation and results. No longer would it be necessary to plan (or guess) in advance virtually all aspects of an experiment. Neither would it be necessary to depend so heavily on very expensive but highly restrictive general-purpose hardware. Experience so far in the MPS program has led to limited, painstaking 
progress achieved in the noninteractive mode. Perhaps the availability of the interactive mode would make possible the rapid progress that has long been hoped for in MSE.

Thus, an MSE Iaboratory aboard a manned space station should contain many of the same facilities as a materials science and engineering laboratory on earth, including facilities for machining, manipulation, fabrication, characterization, and so forth. Power requirements and available materials should be those needed for alteration and repair of apparatus, not just for operation and samples. Many of these facilities could be shared with other activities (e.g., satellite repair) that might be conducted in a space station.

\section{MATERIALS SCIENCE AND ENGINEER ING REQUIREMENTS FOR A SPACE STATION}

This section describes the characteristics and requirements of a space station for optimal use to the MSE community. The development of specific MSE experiments to be conducted on a space station is hampered by rapid evolution of the materials technology industries and the limited MSE flight experience. Even an inspired selection of experiments made at this time might be obsolete before a space station could be available. Consequently, it is more prudent to assess the MSE requirements on a functional basis.

Free-fall is the principal attribute of space exploited in MSE experiments; the secondary attributes are vacuum (level and pumping capacity), radiation, and solar power. To date, all MSE experiments have focused on the exploitation of continuous free-fall, or low-g, and this will continue to be the basis for these proposed requirements.

Experiments in low-g (orbital and suborbital) have demonstrated that a working environment less than $10^{-3} \mathrm{~g}$ can produce substantive changes in convective phenomena and in the relative significance of surface and body forces. Therefore, this $10^{-3} \mathrm{~g}$ will be accepted as a maximum working value. As critical dimensions and parameters are increased, a further reduction in $g$-level may be required simply to maintain the same level of convection. Similarly, more sensitive materials, processes, or geometries require further reductions in g-level. The $g$-level associated with the Space Shuttle is expected to be $10^{-4} \mathrm{~g}$ to $10^{-7} \mathrm{~g}$. Similar $\mathrm{g}$-levels would 
be required in a space station. Moreover, the g-level must be continuous, not intermittent, for the duration of an experiment.

Most materials processing experiments impose a specific thermal geometry on a sample for a period of time-hours and sometimes days. The temperature and scale of an experiment will determine the power requirements, and the time at temperature determines the energy required. Some MSE experiments with sample sizes on the order of a few centimeters have been designed to consume less than $2 \mathrm{~kW}$. A scale-up in size or in temperature would make 4 to $5 \mathrm{~kW}$ for each experimental system and $25 \mathrm{~kW}$ for the total facility realistic goals. Requisite energies would be on the order of $100 \mathrm{~kW}-\mathrm{hr}$ for each experimental system. Comparable cooling capacity would have to be provided.

The weight and size of the materials are negligible compared with that of furnaces, power, control, and data-acquisition hardware. Hardware dedicated to a single experiment is likely to range from 150 to $400 \mathrm{~kg}$, and facility complexes of a larger scale, from 1,000 to 1,500 $\mathrm{kg}$. These masses could be housed in volumes from as little as $0.25 \mathrm{~m}^{3}$ (for a middeck experiment) to facilities that might use 20 to $50 \mathrm{~m}^{3}$. The masses should be housed in volumes of standardized geometry in order to promote the economies of a modular approach.

The data produced by an MSE experiment may be in video or digital forms, but more likely would reside in the specimens themselves. Process control and data-acquisition rates are small when compared with those of remote sensing. The MSE experiment must be free of interference from other facility users-for example in the forms of electromagnetic interference or vibration, particularly below $100 \mathrm{~Hz}$.

\section{CONCLUS IONS}

NASA's MPS program is primarily a scientific program; its contribution will be through the development of better materials and processing methods. Improvements in the quality and scope of the NASA MPS program over the last five years now permit experiments for flight to be selected from a variety of ongoing ground-based programs. The program is now restricted by limited flight opportunities and hardware. 
Present and planned electrophoretic experiments aimed at commercial purification of biologically active substances in space cannot be properly assessed by the Panel for lack of detailed information. However, it does not appear to the Panel that it will be a commercially viable enterprise. Before electrophoresis for commercial purposes is widely promoted as a justification for a space station, NASA should make an in-depth assessment of the process by soliciting the opinion of separations experts and providing them with access to the details of the process.

The Panel concludes that materials science and engineering should not be used as a primary justification for a space station. However, the style or mode of MSE experiment that might be conducted aboard a manned space station would have distinct advantages over that which can be conducted in other microgravity facilities; the advantages would result largely from the potential for real-time adaptive interaction by humans. 


\section{SYSTEM DESIGN}

This chapter is organized into discussions of two subjects: user design requirements, and manned system design issues. For each subject, the recommendations of the Panel are summarized and illustrated. The results emphasize that the human role in space may be the most important system design issue affecting the development of a space station, and that an appropriate first step in the evolution of humans working in space should be the development of a "space service station" capability.

\section{USER DESIGN REQUIREMENTS}

\section{Orbit Considerations}

A space station's orbit should be determined by user requirements and space transportation economics. Users performing onboard materials processing should have no strong orbit preference. Users performing earth sensing require orbits that meet ground coverage, ground track cycle, and local sun angle requirements. Users employing the space station for launch and retrieval of free-flying spacecrafts' will desire an orbit that closely matches their spacecraft's final altitude, orbit inclination, and ascending node location. The space station's orbit, on the other hand, will be constrained, since it must be compatible with resupply by the Space Shuttle.

The approach to orbit selection should begin with a mission model that considers all potential users, and then trades off space station orbit and transfer stage performance in order to capture the maximum number of missions with a single (or few) space station(s). With this type of traffic analysis, a $28.5^{\circ}$ inclination orbit 
would be the choice for the initial space station. There is considerable traffic at higher-inclination orbits, but the traffic is distributed in a way that makes a single space station or space platform less attractive. Hence, the Panel recommends that a polar orbiting facility be part of the earth space station infrastructure--e.g. an unmanned space platform in a sun-synchronous low earth orbit.

\section{Space Station/Platform Modularity and Separability}

The many users of a space station require module isolation in order to enhance ownership, reduce environmental and other interactions, increase military utility, and promote international use. In addition, a modular approach can accommodate the differences between research activities and operational services. From a management standpoint, the use of dedicated modules or sections of the space station for different agencies, governments, or industries is highly desirable. Common use of general-purpose facilities by all users may seriously compound payload integration, design security, and resource allocations. The Panel recommends that the space station employ modularity and flexibility in the allocation of user space and resources.

\section{Information Systems Architecture}

Three principal issues that must be resolved in the design of information systems for a space station are collection and processing of payload data, management of vehicle housekeeping functions, and structuring of the communications network between the station, other space systems, and the ground.

Advances in microcircuit technology, coupled with increased sophistication in sensor performance, have made onboard processing of sensor data both a feasible and an attractive alternative to transmission of large-bandwidth data streams to the ground. Moreover, information from several satellite systems will be available simultaneously, permitting data fusion and increasing data utility. The space station may be used as an intermediate data processing resource between space-borne systems and the ground. In addition, the space station processing center must provide access to both secure and nonsecure users if this capability is to serve both national defense and civil users. 
In summary, the introduction of a space station as an intermediate data processing resource between satellites and the ground would provide the capability to reduce high data rate streams from payloads to low data rate streams relayed directly to users. It would provide the capability to support the fusion of information from several payloads. Key issues of data separation and security must be resolved in order to make a space station multiuser processing center practical.

\section{Other User Requirements}

Many uses of the space station involve the accommodation of science and applications payloads that have different sensitivities. Several areas demand special attention:

Contamination control--i.e., the protection of optical surfaces, detectors (particularly those cryogenically cooled), and thermal control coatings--demands careful system planning. Reaction control jets should produce clean, fully expanded exhaust gases with minimal impingement on sensitive areas; life support waste management should avoid overboard dumps; and all fluid connections must minimize leakage or spillage during servicing operations.

Electromagnetic control (EMC) and radiofrequency interference (RFI) constitute another area where system planning will be required. Radiofrequency sensors used for microwave observation of the earth and for radio astronomy are examples of sensitive systems whose successful operation requires absence of interfering signals. But radiating experiments such as the synthetic-aperture radar can introduce interfering signals into space station systems and other payloads.

Dynamic interactions between individual payloads and between payloads and the space station will require careful treatment.

Various science experiments will require precision pointing and a highly stable platform. In some cases, the experiments may require greater pointing and stability capability than is practical to provide for the entire station; the accommodation can still be provided through the use of precision mounting points. The design of the space station must provide sufficiently high isolation 
between the movements of the host vehicle appendages and the humans within the pressurized modules and those payloads requiring high pointing accuracy and stability.

Power demands for support of payloads considered by NASA studies are as high as $75 \mathrm{~kW}$ (average). In addition, it will be necessary to deal with emergency station needs, eclipse effects, peak power demands of certain payloads, and demand conflicts. Furthermore, the power provided to users will need to be clean--i.e., free of switching transients and high-frequency interference.

\section{MANNED SYSTEM DESIGN ISSUES}

The extent and nature of the human role in space is considered by the Panel to be a most fundamental system design issue affecting the development of the space station.

\section{Character of Human Presence in Space}

The majority of space activities to date have been conducted by remote control where, after delays of minutes or even days, decisions are made on the ground that are then implemented. However, astronauts have performed some experiments where the response was truly in real-time. Man's role in space should be considered in the context of three modalities: delayed response, telepresence, * and physical human presence.

Man has unique capabilities of observation and manipulation that today's technology cannot reproduce. Although robotics and the technology of telepresence are progressing, some human capabilities will remain unique indefinitely.

Although delayed response is an important mode, the primary space station choice is between physical presence and telepresence. Physical presence offers the potential advantages of timeliness, adaptability, dexterity, and autonomy; telepresence offers the potential advantages of efficiency, collaboration, and use of larger human resources.

*Telepresence can be defined as the use of rea1-time communications, visual display, and remote control to provide an operator on the earth's surface the capability to carry out complex operations within the space station. 
Functions for which data transmission delay is satisfactory are uncertain, but may include many human functions in space. However, the degree to which robots can perform all functions will increase on $1 y$ as the technology advances. Many data evaluation and target selection functions can be performed via telepresence, but considerable development will be required to produce a teleoperator with scanning and focusing eyes, facile arms, and pressure-sensitive fingers to perform complex on-orbit as sembly.

\section{Technical Support for Expanding Human Capabilities in Space}

Man's effectiveness in space is limited by the performance of his spacesuits, tools, and maneuvering units. Without significant improvements in these areas, much of man's potential utility will be lost. The Panel recommends that technical advances in each of these areas should be an early objective and should precede establishment of large space stations housing many astronauts.

\section{CONCLUS IONS}

The human role in space may be the most important system design issue affecting the development of a space station. Both physical human presence in space and telepresence ( $i . e$. , the use of real-time cormunications to carry out complex activities) are important. The Panel recommends that the technologies for physical presence and telepresence be developed with comparable emphasis.

The second Panel conclusion reflects the potential value of humans and the space station as an in-orbit service facility. Functions would include, but not be limited to, spacecraft and instrument repair and servicing, change or addition of payload instruments and spacecraft subsystems, and replenishment of expendables. The first step in the evolution of humans working in space should be the development of a "space service station" capable of tending all compatible spacecraft.

As a third conclusion, the Panel recommends that NASA develop and promulgate design rules for a number of concepts. Specifically, there is need for rules concerning modular design; rules covering the introduction of new technology; and rules governing the definition of interfaces between major systems and between subsystems. 


\section{9}

Finally, the Panel believes that a space station development program should make provision for technology advance or growth during the development period.

Construction of a space station using off-the-shelf technology, although less costly initially, may not provide adequate capability to support requirements for onboard data processing, user needs, growth potential, or sufficient operational utility. 
The National Academy Press was created by the National Academy of Sciences to publish the reports issued by the Academy and by the National Academy of Engineering, the Institute of Medicine, and the National Research Council, all operating under the charter granted to the National Academy of Sciences by the Congress of the United States. 